\title{
Cross-Adaptation: Heat and Cold Adaptation to Improve Physiological and Cellular Responses to Hypoxia
}

\author{
Oliver R. Gibson ${ }^{1,2} \cdot$ Lee Taylor $^{3,4} \cdot$ Peter W. Watt $^{2} \cdot$ Neil S. Maxwell $^{2}$
}

Published online: 7 April 2017

(c) The Author(s) 2017. This article is an open access publication

\begin{abstract}
To prepare for extremes of heat, cold or low partial pressures of oxygen $\left(\mathrm{O}_{2}\right)$, humans can undertake a period of acclimation or acclimatization to induce environment-specific adaptations, e.g. heat acclimation (HA), cold acclimation (CA), or altitude training. While these strategies are effective, they are not always feasible due to logistical impracticalities. Cross-adaptation is a term used to describe the phenomenon whereby alternative environmental interventions, e.g. HA or CA, may be a beneficial alternative to altitude interventions, providing physiological stress and inducing adaptations observable at altitude. HA can attenuate physiological strain at rest and during moderate-intensity exercise at altitude via adaptations allied to improved $\mathrm{O}_{2}$ delivery to metabolically active tissue, likely following increases in plasma volume and reductions in body temperature. CA appears to improve physiological responses to altitude by attenuating the autonomic response to altitude. While no cross-acclimation-derived exercise performance/capacity data have been measured following CA, post-HA improvements in performance underpinned by aerobic metabolism, and
\end{abstract}

Oliver R. Gibson

oliver.gibson@brunel.ac.uk

1 Centre for Human Performance, Exercise and Rehabilitation (CHPER), Brunel University London, Uxbridge, UK

2 Welkin Human Performance Laboratories, Centre for Sport and Exercise Science and Medicine (SESAME), University of Brighton, Denton Road, Eastbourne, UK

3 Athlete Health and Performance Research Centre, ASPETAR, Qatar Orthopaedic and Sports Medicine Hospital, Doha, Qatar

4 School of Sport, Exercise and Health Sciences, Loughborough University, Loughborough, UK therefore dependent on $\mathrm{O}_{2}$ delivery at altitude, are likely. At a cellular level, heat shock protein responses to altitude are attenuated by prior HA, suggesting that an attenuation of the cellular stress response and therefore a reduced disruption to homeostasis at altitude has occurred. This process is known as cross-tolerance. The effects of CA on markers of cross-tolerance is an area requiring further investigation. Because much of the evidence relating to cross-adaptation to altitude has examined the benefits at moderate to high altitudes, future research examining responses at lower altitudes should be conducted, given that these environments are more frequently visited by athletes and workers. Mechanistic work to identify the specific physiological and cellular pathways responsible for cross-adaptation between heat and altitude, and between cold and altitude, is warranted, as is exploration of benefits across different populations and physical activity profiles.

\section{Key Points}

Adaptations to heat favourably reduce the physiological strain of subsequent hypoxia, largely via improvements to the cardiovascular system.

Adaptations to cold reduce the physiological strain of subsequent hypoxia by reducing sympathetic responses attenuating the autonomic responses.

At a cellular level, heat adaptations reduce the necessity to transcript further heat shock protein responses for cytoprotection, although the cellular adaptations to cold stress in subsequent hypoxia in humans remain largely unknown. 


\section{Introduction}

Athletic pursuits or occupational requirements can necessitate human exposure to a variety of environments. Human research has long considered the capacity for humans to respond and adapt to stressful environments, notably hot $[1,2]$ and cold conditions [3, 4], and low oxygen $\left(\mathrm{O}_{2}\right)$ [high altitude] environments [5,6]. These environments elicit stimuli-specific responses upon acute exposure, e.g. sweating in the heat [7], shivering in the cold [8] or elevating ventilation at altitude [9], with adaptation to each specific environment positively influencing these discrete responses. In addition to stimuli-specific physiological responses, environmental conditions also elicit shared physiological responses, e.g. acutely increased heart rate (HR) in cold [8], hot [7] and altitude environments [9]. Given the long-standing appreciation of these responses, it is surprising that work has only recently begun considering interactions between environment stressors in vivo in humans [10]. Research has begun to identify pathways by which genericrather than environment-specific effector adaptations made in one environment can be physiologically beneficial within another. This work initially acknowledged that altitudederived adaptations [11-15] can be beneficial during normothermic, sea-level exercise, an observation that now extends to heat-induced adaptations [16]. Recent reviews have proposed that heat-induced adaptations attained during heat acclimation/acclimatisation (HA) are physiologically beneficial in hypoxic/altitude environments [17-19], with experimental work now supportive of these hypotheses [20-23]. Conversely, less attention has been given to the role that cold adaptations attained during cold acclimation/acclimatisation (CA) [24] may have on the physiological responses to hypoxia/altitude, despite experimental evidence in humans also supporting this phenomenon [25].

It is the intention of this review to consider the body of evidence supporting thermal adaptations, i.e. those made in response to repeated heat or cold, on the subsequent physiological responses to hypoxia, a phenomenon that can be defined as cross-adaptation [26], as an alternative method for preparing individuals for altitude. At the present time, the paucity of data where environmental stressors are combined necessitates the exclusion of discussion allied to cross-adaptation between HA into cold, hypoxia stress, and CA into hot, hypoxic stress, although clearly HA retains relevance in hot, hypoxic environments, as does $\mathrm{CA}$ in cold, hypoxic environments.

\subsection{Cross-Adaptation Nomenclature}

Within cross-adaptation (a generic term to describe the phenomenon) two distinct components to describe the induced changes have emerged-cross-acclimation/ acclimatisation and cross-tolerance. Cross-acclimation (adaptation derived from a simulated environment [26]) or cross-acclimatisation (adaptation derived from a natural environment [26]) are adopted to define specific adaptations made at a physiological level due to commonality with typical descriptions of the acquired HA or CA phenotype $[7,8,27]$. Further to the use of cross-acclimation, cross-tolerance is the adopted nomenclature appropriate to describe cellular and molecular pathways relevant to adaptations between thermal and hypoxic environments due to common pathways with thermotolerance (also known as acquired cellular thermotolerance [28, 29]). While this nomenclature can be used in human and animal experimental work, it is the intention of this review to focus only on cross-adaptation experimental work conducted in humans.

\section{Heat to Hypoxia Cross-Adaptation}

\subsection{Heat to Hypoxia Cross-Acclimation}

\subsubsection{Mechanisms by Which Heat to Hypoxia Cross- Acclimation May Occur}

The heat-acclimated phenotype presents with improved effector heat loss mechanisms to overcome negative physiological responses to acute heat stress and consequently maintain internal endogenous temperature and central blood pressure [27] (see Sawka et al. [7] for a review of the negative physiological and performance responses to heat stress). The necessity to maintain blood pressure and perfusion to the exercising muscle, brain, and skin during heat stress results from an increased fraction of cardiac output $(Q)$ distributed peripherally to the cutaneous circulation to facilitate heat loss to the environment [30-33]. At a physiological level, when under heat stress the maintenance of central and peripheral blood pressure is supported by a complex interaction of exercise- and temperature-induced hypervolaemia [34], specifically the plasma volume (PV) component of the blood [35], improved myocardial compliance [36], increased autonomic vasomotor control to regulate arterial and central venous pressure [37], sudomotor activation and efficiency [38], and reductions in onset thresholds for stimulating heat loss pathways [7]. The time course of each individual adaptation varies with a general trend for an increased magnitude of adaptation over time [39], with the reader directed to a meta-analysis describing the magnitude of heat adaptations in response to different HA regimes for further information [40]. Each of the described HA adaptations has the potential to favourably augment physiological responses to exercise in hypoxia, the most potent 
appearing to be those allied to cardiovascular, rather than thermoregulatory, physiology, given the likely compensable heat stress of most hypoxic/altitude environments [41]. The exception to this notion is when protective clothing/uniform is worn at altitude, since this will inhibit or mitigate evaporative heat loss, consequently posing a thermoregulatory challenge [42].

The proposal that HA might improve physiological responses and exercise performance in temperate conditions, a subtle form of cross-adaptation, has been discussed elsewhere [16], with debate questioning the magnitude of improvement in athletic performance in temperate conditions following HA [43-46]. The benefits for athletic performance remain equivocal [47-49]; however, various exercise-heat stress interventions, more logistically appealing than travelling to altitude, have been able to induce favourable physiological responses during exercise, e.g. HA [49-51], sauna exposure [52, 53], and hot-water immersion [54, 55]. These interventions induce adaptations, including PV expansion, reduced body temperature, improved blood distribution and enhanced exercise performance, which may also prove beneficial in hypoxia $[50,52,54]$. Of these different strategies, HA remains the most well-understood, with the greatest volume of data supporting the attainment of desirable physiological adaptations [7, 27, 39, 40]. HA-derived PV expansion has been proposed as a fundamental mechanism to improve physiological responses and performance at altitude [19], with erythropoietic effects of hypervolaemia deemed unlikely [43], as recently demonstrated using the optimised carbon monoxide rebreathing technique during HA [20, 48].

Heat stress and hypoxia compromise $\mathrm{O}_{2}$ delivery to exercising muscle $[56,57]$, however different pathways are responsible. Under heat stress, reductions in $\dot{Q}$ distributed to exercising muscle is debilitative [32]. In hypoxia, despite equal or greater $\dot{Q}$ at a fixed exercise intensity, a reduced blood arterial oxygen content $\left(\mathrm{CaO}_{2}\right) /$ partial pressure of oxygen $\left(\mathrm{PO}^{-2}\right)$ entering the muscle concomitantly reduces exercise capacity due to the increased relative intensity of the task concurrent to a $6.3 \%$ decline in maximal oxygen uptake $\left(\dot{V} \mathrm{O}_{2 \max }\right)$ with each $1000 \mathrm{~m}$ elevation in altitude [58]. It is noteworthy that the negative implications of altitude are further magnified with increasing aerobic training status due to increase muscular $\mathrm{O}_{2}$ utilisation [59] and incomplete pulmonary gas exchange with a higher $\dot{Q}$ [60]. In hypoxia the $\mathrm{PO}_{2}$ delivered to the muscle is reduced, becoming more pronounced with increasing ascents, and therefore limiting exercise performance [59]. Despite different limiting pathways in heat and hypoxia, the outcome is similar; reduced $\mathrm{O}_{2}$ is available for cellular respiration in the muscle, facilitating a decrease in the absolute maximal aerobic capacity and an increase in the relative intensity of a fixed task when performed in a normoxic, normothermic environment. Under conditions where $\mathrm{O}_{2}$ delivery is reduced, the body can maintain the required $\dot{V} \mathrm{O}_{2}$ at the muscle [32, 57] and brain [61, 62], via increased $\mathrm{O}_{2}$ utilisation. While increasing $\dot{Q}\left(\mathrm{O}_{2}\right.$ delivery) is a beneficial response to offset reductions in $\mathrm{PO}_{2}$ partially, this response is finite. The aforementioned dehydration experiments $[32,57,61,62]$ are an effective insight into the benefits of HA-induced PV expansion to increase $\dot{Q}$ and maintain $\mathrm{O}_{2}$ delivery in hypoxia.

\subsubsection{Evidence of Heat to Hypoxia Cross-Acclimation}

Comparisons between cross-acclimation experiments can be problematic, given the potential for the use of different HA protocols and durations, as the intervention, ineffective matching of control groups, timing of post-testing, and interindividual variation can each influence the observed adaptive response (see Taylor [27] for an overview of HA methods, and Tyler et al. [40] for a meta-analysis of the magnitude of adaptation relative to the timecourse of HA). Fortunately, at this early stage, cross-acclimation research has been largely consistent in the methods implemented, with similar timescales for the intervention employed. One difference exists in the use of fixed or isothermic HA protocols, although current evidence suggests these protocols generally possess similar adaptive capacities [51, 63].

Heled et al. [23] were the first to describe the effects of HA on exercise performance in hypoxia. In moderately trained humans, HA $(12 \times 120$ min sessions of walking at $30 \% \dot{V} \mathrm{O}_{2 \max }$ ) did not induce changes in $\dot{V} \mathrm{O}_{2 \max }$ (pre-HA $\left[57.0 \pm 3.7 \mathrm{~mL} \mathrm{~kg}^{-1} \mathrm{~min}^{-1}\right]$ compared with post-HA [57.1 $\left.\pm 2.9 \mathrm{~mL} \mathrm{~kg}^{-1} \mathrm{~min}^{-1}\right]$ ) at a moderate altitude (2400 $\mathrm{m}$; fraction of inspired oxygen $\left.\left[\mathrm{FiO}_{2}\right] \approx 0.156\right)$. However, peripheral oxygen saturation $\left(\mathrm{SpO}_{2} \%\right)$ did improve at $7 \mathrm{~km} \mathrm{~h}^{-1}$ (pre-HA $86.5 \pm 2 \%$; post-HA $88.0 \pm 2 \%$ ), and $\mathrm{HR}$ at the onset of blood lactate accumulation ( 4 mmol. $\left.\mathrm{L}^{-1}\right)$ during an incremental treadmill test $\left(+1 \mathrm{~km} \cdot \mathrm{h}^{-1}\right.$ every $\left.3 \mathrm{~min}\right)$ was delayed (pre-HA [ $160 \mathrm{~b} \mathrm{~min}^{-1}$ ] compared with post-HA $\left.\left[\sim 170 \mathrm{~b} \mathrm{~min}^{-1}\right]\right)$, suggesting that, although not specifically reported, typical HA phenotypic adaptations (e.g. PV expansion, improved myocardial compliance and reduced cardiovascular strain [40]) had likely occurred, and thus facilitated improvements in a moderate intensity domain (Table 1). Although providing seminal data at an altitude commonly used for training and competition [15], the exposure was relatively brief ( $<30 \mathrm{~min}$ ), lacking an appropriate control group for comparisons with the experimental group, and the measured physiological responses to the intervention were minimal, therefore the findings have limited capacity for mechanistic 
Table 1 Heat to hypoxia cross-acclimation experimental data

\begin{tabular}{|c|c|c|c|c|}
\hline Study, year & Heat acclimation protocol & $\begin{array}{l}\text { Adaptations to heat } \\
\text { acclimation }\end{array}$ & Hypoxic protocol & Improved responses to hypoxia \\
\hline $\begin{array}{l}\text { Heled et al. } \\
{[23], 2012}\end{array}$ & $\begin{array}{l}12 \text { days } \\
120 \text { min day }{ }^{-1} \\
40{ }^{\circ} \mathrm{C} 40 \% \mathrm{RH} \\
{[\text { Fixed] Walking @ 30\% }} \\
\dot{V} \mathrm{O}_{2 \text { peak }}\end{array}$ & $\begin{array}{l}\text { Peak HR }=\downarrow 12 \\
\quad \text { b } \min ^{-1} \\
\text { Peak } \\
\quad T_{\text {rec }}=\downarrow 0.24^{\circ} \mathrm{C}\end{array}$ & OBLA test $\left(\mathrm{FiO}_{2}=0.15 ; \sim 2500 \mathrm{~m}\right)$ & $\begin{array}{l}\mathrm{HR} @ \mathrm{OBLA}=\downarrow 10 \mathrm{~b} \mathrm{\textrm {min } ^ { - 1 }} \\
\mathrm{SpO}_{2} @ 7 \mathrm{~km} \mathrm{~h}^{-1}=\uparrow 1.5 \%\end{array}$ \\
\hline $\begin{array}{l}\text { Lee et al. } \\
\text { [66], } 2014\end{array}$ & $\begin{array}{l}3 \text { days } \\
75 \text { min day }{ }^{-1} \text { (including } \\
15 \text { min preliminary } \\
\text { rest) } \\
40{ }^{\circ} \mathrm{C} 20 \% \mathrm{RH} \\
{[\text { Fixed] Cycling @ } 50 \%} \\
\dot{V} \mathrm{O}_{2 \text { peak }}\end{array}$ & $\begin{array}{l}\text { Heat } \\
\quad \text { tolerance }=\uparrow 3 \mathrm{~min} \\
\text { Sweat rate }=\uparrow 23 \% \\
\text { Plasma } \\
\quad \text { volume }=\uparrow 4.6 \%\end{array}$ & $\begin{array}{l}15 \text { min @ rest } \\
60 \text { min @ 50\% } \dot{V} \mathrm{O}_{2 \text { peak }}\left(\mathrm{FiO}_{2}=0.14\right. \\
\sim 3300 \mathrm{~m})\end{array}$ & $\begin{array}{l}\text { Peak HR }=\downarrow 9 \mathrm{~b} \mathrm{~min}^{-1} \\
\text { Mean } \mathrm{HR}=\downarrow 9 \mathrm{~b} \cdot \mathrm{min}^{-1} \\
\text { Peak } T_{\text {rec }}=\downarrow 0.3{ }^{\circ} \mathrm{C} \\
\text { Mean } T_{\text {rec }}=\downarrow 0.2^{\circ} \mathrm{C} \\
\text { Peak } T_{\text {skin }}=\uparrow 0.6^{\circ} \mathrm{C} \\
\text { Mean } T_{\text {skin }}=\uparrow 0.9^{\circ} \mathrm{C}\end{array}$ \\
\hline $\begin{array}{l}\text { Gibson } \\
\text { et al. [20], } \\
2015\end{array}$ & $\begin{array}{l}10 \text { days } \\
90 \text { min day } \\
40{ }^{-1} \mathrm{C} 40 \% \mathrm{RH} \\
{[\mathrm{ISO} \text { Cycling @ } 65 \%} \\
\dot{V} \mathrm{O}_{2 \text { peak }}\end{array}$ & $\begin{array}{l}\text { Resting HR }=\downarrow 18 \\
\text { b } \text { min }^{-1} \\
\text { Resting } \\
T_{\text {rec }}=\downarrow 0.49{ }^{\circ} \mathrm{C} \\
\text { Sweat rate }=\uparrow 48 \% \\
\text { Plasma } \\
\text { volume }=\uparrow 14.7 \%\end{array}$ & $\begin{array}{l}10 \text { min rest } \\
10 \text { min cycling @ } 40 \% \dot{V} \mathrm{O}_{2 \text { peak }} \\
10 \text { min cycling @ } 65 \% \dot{V} \mathrm{O}_{2 \text { peak }} \\
\left(\mathrm{FiO}_{2}=0.12 ; \sim 4500 \mathrm{~m}\right)\end{array}$ & $\begin{array}{l}\mathrm{HR} @ 65 \% \dot{V} \mathrm{O}_{2 \text { peak }}=\downarrow 12 \\
\mathrm{~b} \min ^{-1} \\
\mathrm{SpO}_{2} @ 65 \% \dot{V} \mathrm{O}_{2 \text { peak }}=\uparrow 3 \% \\
\dot{V} \mathrm{O}_{2} / \mathrm{HR} @ \\
\mathrm{rest}=\uparrow 0.5 \mathrm{~mL} \mathrm{bt}^{-1} \\
\dot{V} \mathrm{O}_{2} / \mathrm{HR} @ 65 \% \\
\dot{V} \mathrm{O}_{2 \text { peak }}=\uparrow 1.3 \mathrm{~mL} \mathrm{bt}^{-1} \\
\mathrm{RER} @ \text { rest }=\downarrow 0.06\end{array}$ \\
\hline $\begin{array}{l}\text { White et al. } \\
\text { [22], } 2016\end{array}$ & $\begin{array}{l}10 \text { days } \\
2 \times 50 \text { min day }{ }^{-1} \\
(10 \text { min rest interval }) \\
40{ }^{\circ} \mathrm{C} 55 \% \mathrm{RH}(1600 \mathrm{~m} \\
\text { altitude }) \\
{[\text { Fixed] Cycling @ } 50 \%} \\
\dot{V} \mathrm{O}_{2 \text { peak }}\end{array}$ & $\begin{array}{l}\text { Exercise } \mathrm{HR}=\downarrow 21 \\
\quad \mathrm{~b} \min ^{-1} \\
\text { Exercise } \\
\quad T_{\text {rec }}=\downarrow 0.5^{\circ} \mathrm{C} \\
\text { Plasma } \\
\quad \text { volume }=\uparrow 1.9 \% \\
\mathrm{RPE}=\downarrow 3 \\
\mathrm{TS}=\downarrow 1.0\end{array}$ & $\begin{array}{l}16.1 \mathrm{~km} \text { cycling } \mathrm{TT}\left(\mathrm{FiO}_{2} \approx 0.12 \text {; }\right. \\
4350 \mathrm{~m})\end{array}$ & TT time $=\downarrow 1.6 \%(p=0.07)$ \\
\hline $\begin{array}{l}\text { Lee et al. } \\
\text { [21], } 2016\end{array}$ & $\begin{array}{l}10 \text { days } \\
75 \text { min day }{ }^{-1} \text { (including } \\
15 \text { min rest) } \\
40{ }^{\circ} \mathrm{C} 25 \% \mathrm{RH} \\
\text { [Fixed] Cycling @ 50\% } \\
\dot{V} \mathrm{O}_{2 \text { peak }}\end{array}$ & $\begin{array}{l}\text { Mean } \mathrm{HR}=\downarrow 14 \\
\quad \mathrm{~b} \min ^{-1} \\
\text { Resting } \\
\quad T_{\text {rec }}=\downarrow 0.26{ }^{\circ} \mathrm{C} \\
\text { Exercise } \\
\quad T_{\text {rec }}=\downarrow 0.54{ }^{\circ} \mathrm{C} \\
\text { Plasma } \\
\quad \text { volume }=\uparrow 3.5 \% \\
\text { Sweat rate }=\uparrow 88 \% \\
\mathrm{TS}=\downarrow 0.9\end{array}$ & $\begin{array}{l}40 \text { min @ } 50 \% \dot{V} \mathrm{O}_{2 \text { peak }} \text {, then } 16.1 \mathrm{~km} \\
\text { cycling TT }\left(\mathrm{FiO}_{2}=0.14 ; \sim 3300 \mathrm{~m}\right)\end{array}$ & $\begin{array}{l}\text { Mean } \mathrm{HR}=\downarrow 9 \mathrm{~b} \mathrm{~min}^{-1} \\
\text { Mean } \mathrm{SpO}_{2}=\uparrow 2 \% \\
\dot{V} \mathrm{O}_{2} / \mathrm{HR}=\uparrow 0.7 \mathrm{~mL} \mathrm{bt}^{-1} \\
\text { Mean } T_{\text {rec }}=\downarrow 0.15^{\circ} \mathrm{C} \\
\text { TT time }=\downarrow 4.7 \%\end{array}$ \\
\hline
\end{tabular}

[Fixed] denotes fixed-intensity protocol, [ISO] denotes isothermic/controlled hyperthermia protocol, $\mathrm{FiO}_{2}=$ fractional inspired oxygen content, $H R$ heart rate, $O B L A$ onset of blood lactate accumulation, $R H$ relative humidity, $R E R$ respiratory exchange ratio, $R P E$ rating of perceived exertion, $\mathrm{SpO}_{2}$ peripheral oxygen saturation, $T_{\text {rec }}$ rectal temperature, $T S$ thermal sensation, $T_{\text {skin }}$ skin temperature, $T T$ time trial, $\dot{V} \mathrm{O}_{2 p e a k}$ peak oxygen uptake, $\uparrow$ indicates increase, $\downarrow$ indicates decrease

interpretation, or application for populations who sojourn to altitudes for long durations.

It has recently been observed that comparable HA regimes induce improved physiological responses [20, 21], and may [21], or may not [22], improve exercise performance in hypoxia. The difference between these comparable interventions is potentially the large $(+14.7 \%$ [20] $)$ to moderate $(+3.5 \%$ [21]), or negligible (1.9\% [22]), PV expansion (Table 1). It was first shown that $10 \times 90 \mathrm{~min}$ sessions of isothermic HA attenuates physiological responses to hypoxia $\left(\mathrm{FiO}_{2}=0.12\right.$ [20]). Additionally, post-HA, reductions in exercising $(65 \%$ peak oxygen uptake $\left.\left[\dot{V} \mathrm{O}_{2 \text { peak }}\right]\right)$ HR $\left(-12 \mathrm{~b} \mathrm{~min}^{-1}\right)$ in hypoxia in response to the same absolute workload were concurrent 
with improved $\mathrm{SpO}_{2}(+3 \%)$, and increased $\mathrm{O}_{2}$ pulse $\left(\dot{V} \mathrm{O}_{2} /\right.$ $\left.\mathrm{HR} ; \quad+0.5 \mathrm{~mL} \mathrm{bt}^{-1}\right)$. Improvements in respiratory exchange ratio (RER) at rest $(-0.06, p=0.04)$ and a trend for improvements during exercise at $65 \% \dot{V} \mathrm{O}_{2 \text { peak }}(-0.05$, $p=0.19$ ) suggested a shift towards lipolysis had also occurred. These responses were improvements from equivalent pre-HA tests, and were in comparison with normothermic training controls. Mechanistically, a 14.7\% expansion of $\mathrm{PV}$ and $\sim 0.5{ }^{\circ} \mathrm{C}$ reduction in core temperature accompanied these responses. The authors concluded [20], in support of earlier reviews [17, 19], that while reduced core temperature was beneficial at facilitating a leftward shift in the oxyhaemoglobin dissociation curve, a more potent mechanism was likely to be the PV expansion due to the capacity for HA to maintain desirable rates of $\mathrm{O}_{2}$ perfusion at the exercising muscles at altitude.

Mechanistically increased PV facilitates maintenance of $\mathrm{SpO}_{2}$ following $\mathrm{HA}$, with no apparent change in $\dot{\mathrm{V}} \mathrm{O}_{2}$ [20]. This is likely due to reductions in HR and blood viscosity affording a greater erythrocyte alveolar transit time [60]. These post-HA responses are analogous to that observed in well-trained individuals possessing a typically larger $Q$, and reduced pulmonary gas exchange time leading to greater desaturation at higher exercise intensities [60]. A prolonged erythrocyte transit time facilitates a more complete resaturation within the pulmonary system [60, 64]. While also beneficial in normoxia $[43,44]$, the PV response is likely to be more pertinent in hypoxia due to further reduced $\mathrm{SpO}_{2}$. Support for a PV-mediated mechanism in cross-acclimation is derived from HA interventions that did not induce hypervolaemia, resulting in no significant improvements in aerobic exercise performance in hypoxia [22]. Some caution should be applied when interpreting experiments where $\mathrm{PV}$ is estimated absent of the measurement of red cell mass, i.e. those where $\Delta \mathrm{PV}$ is determined based on calculations from measured haematocrit and haemoglobin concentrations only, rather than using a technique such as carbon monoxide rebreathing.

Over $10 \times 100 \mathrm{~min}$ sessions of a fixed-intensity $\left(\sim 55 \% \dot{V} \mathrm{O}_{2 \max }\right)$ HA intervention [22], White et al. [22] observed that while not detrimental to performance in hypoxia, HA failed to provide more explicit evidence for cross-acclimation-derived performance improvements at altitude. In that experiment, only a $1.9 \%$ increase in PV and $1.6 \%$ improvement in performance $(p=0.07)$ was observed [22]. These data contrast work suggesting that HA reduces physiological strain in hypoxia [20, 21], and data by Lorenzo et al. [49], who demonstrated beneficial effects of HA in hot and cool conditions. The disparity in the results of the studies by Gibson et al. [20] and White et al. [22] does not entirely diminish confidence in the cross-acclimation response. Within the analysis of White et al. [22], it was reported that PV increased in five participants but decreased in three. Individual $16 \mathrm{~km}$ time trial (TT) data after HA from White et al. [22] showed that seven of eight subjects improved their TT performance, suggesting individual variation should be considered and that variation in PV expansion could have contributed to the trend towards a significant performance improvement in hypoxia. The duration required to complete the $16 \mathrm{~km}$ TT after HA decreased by $28 \mathrm{~s}$, with magnitude-based inferences suggesting that the effect of HA was $96.5 \%$ 'likely beneficial' to performance at $4350 \mathrm{~m}$, providing further confidence in the efficacy of the intervention [22]. Additionally, it is notable that participants were all residents at altitude of $1500-1600 \mathrm{~m}$ and likely partially acclimatised to the low $\mathrm{O}_{2}$. This may have also diminished the magnitude of response. Finally, while no difference in end-exercise $\mathrm{HR}, \mathrm{SpO}_{2}$ and perceived exertion were observed following the HA intervention [22], this is not surprising as the power output was increased for these individuals. Had the participants performed a fixed workload task, it is likely that the physiological responses would be improved with HA, as observed by Gibson et al. [20].

Some limitations exist that may generate individual variation in acclimation response, and mitigated the observation of undisputable evidence for cross-acclimation within the experiment [22]. These include the timing of the post-testing ( 8 days after HA), thus allowing PV expansion to decay [27], the pre-existing altitude habitation and training of participants, and implementation of a fixed, rather than isothermic, HA regime that maintains the potentiating stimuli for physiological adaptation to a greater extent [51, 63]. Regrettably, no control group was included by White et al. [22] to give confidence of a true HA versus training effect. Nonetheless, the hypoxic trials of White et al. [22] and Gibson et al. [20] were performed at comparable altitudes of $4000-4350 \mathrm{~m}$ and utilised comparable exposure durations ( $\sim 30-40 \mathrm{~min})$. Given the 'trend for' [22] and observed statistical significance [20], further work is warranted to elucidate the full physiological and performance improvements induced by HA in hypoxia. A summary of the identified mechanisms are presented in Fig. 1.

Lacking the inclusion of a matched normothermic, normoxic training group as found in the study by Gibson et al. [20], the study by White et al. [22] was also unable to determine differences between the adaptive capacity of HA and an equivalent altitude/hypoxic training protocol. This is essential to determine whether HA is a viable alternative to hypoxic/altitude training. This was addressed by Lee et al. [21], who utilised a 10-day, fixed-intensity $(\sim 50 \%$ $\left.\dot{V} \mathrm{O}_{2 \max }\right)$ HA intervention whereby participants performed $10 \times 60 \mathrm{~min}$ sessions of exercise at a workload 


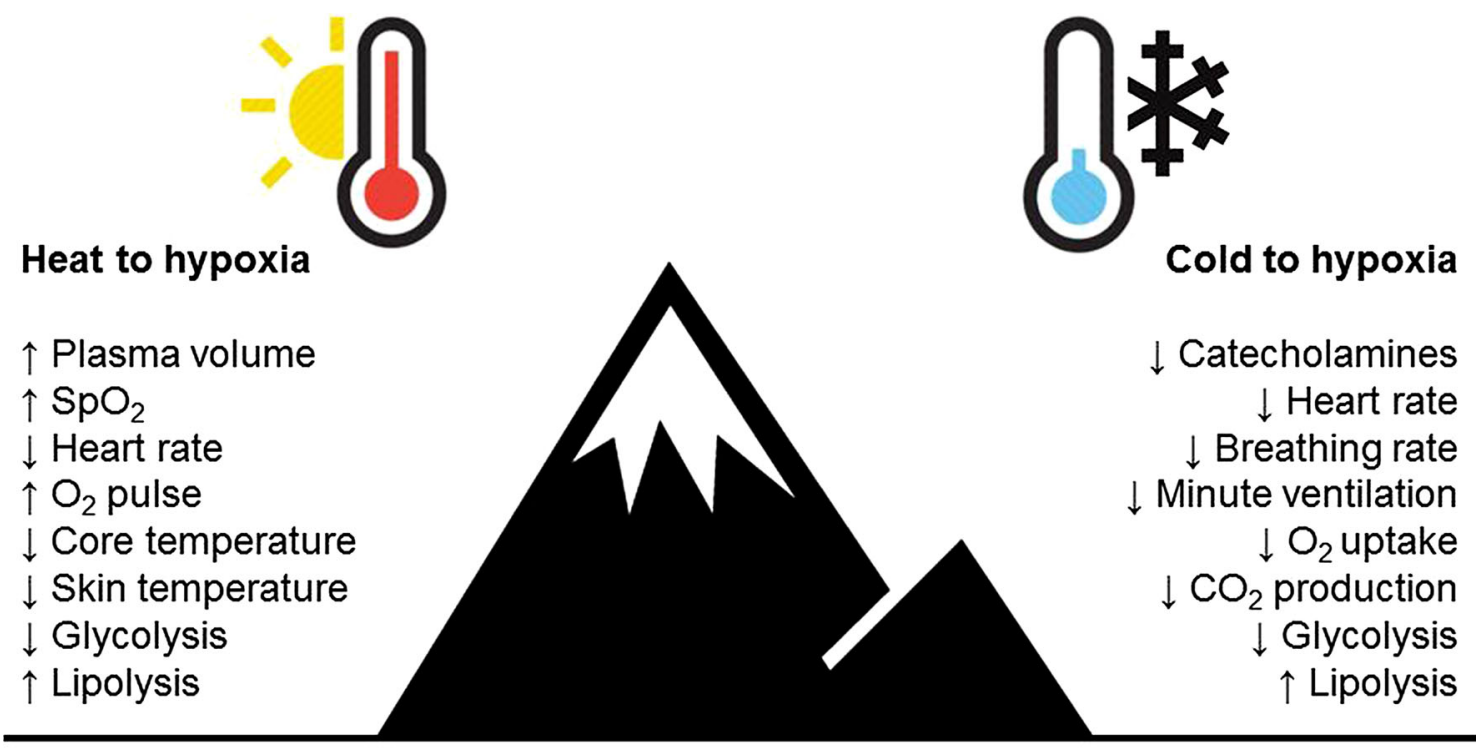

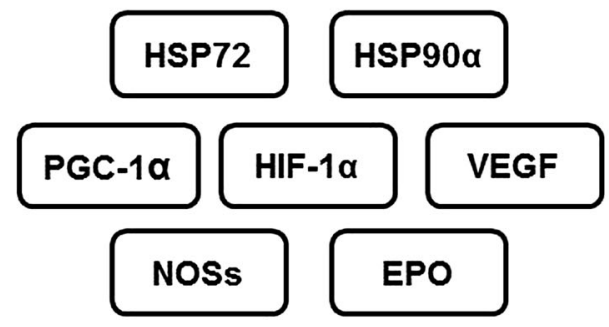

Fig. 1 Identified mechanisms for cross-acclimation between heat and hypoxia (left), cold and hypoxia (right), and identified molecular targets relevant to cross-tolerance in hypoxia (bottom). CIRP coldinducible RNA-binding protein, $\mathrm{CO}_{2}$ carbon dioxide, $E P O$ erythropoietin, $H I F$ hypoxia-inducible factor, $H S P$ heat shock protein, NOSs

corresponding to $50 \%$ of their normothermic, normoxic

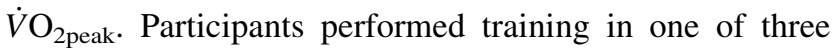
environments: the control group trained in normothermic normoxia $\left(18^{\circ} \mathrm{C}, \quad 35 \%\right.$ relative humidity $[\mathrm{RH}]$ $\mathrm{FiO}_{2}=0.21$ ); a second group trained in hot conditions, i.e. $\mathrm{HA}\left(40{ }^{\circ} \mathrm{C}, 25 \% \mathrm{RH} \mathrm{FiO}_{2} \approx 0.21\right)$; and the third group trained in hypoxic conditions, i.e. hypoxic/altitude training $\left(18{ }^{\circ} \mathrm{C}, 35 \% \mathrm{RH} \mathrm{FiO}{ }_{2}=0.14[\sim 3300 \mathrm{~m}]\right)$ [21]. No benefit in a post-training hypoxic stress test (40 min cycling at $50 \%$ of normoxic $\dot{V} \mathrm{O}_{2 \text { peak }}$ in $\left.\mathrm{FiO}_{2}=0.14[\sim 3300 \mathrm{~m}]\right)$ was observed in control conditions; however, hypoxic training induced a reduction in exercising HR $(-14$ $\left.\mathrm{b} \mathrm{min}^{-1}\right)$. HA elicited an equivalent reduction in exercising HR to that of hypoxic training $\left(-14 \mathrm{~b} \mathrm{~min}^{-1}\right)$. The HAmediated reduction in HR was also observable at rest $(-11$ $\mathrm{b} \mathrm{min}^{-1}$ ). Additionally, core temperature decreased (rest $=-0.3{ }^{\circ} \mathrm{C}$, exercising $=-0.5{ }^{\circ} \mathrm{C}$ ) to a similar extent of that of Gibson et al. [20] (see Table 1).

These adaptations were congruous with those seen in other studies investigating the independent and combined

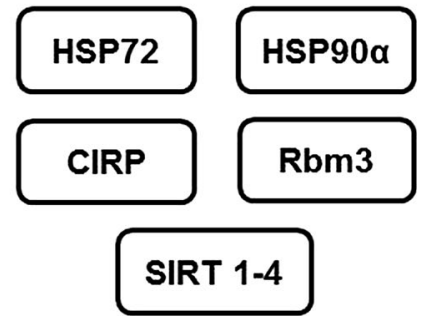

nitric oxide synthases, $\mathrm{O}_{2}$ oxygen, $P G C$ peroxisome proliferatoractivated receptor gamma coactivator, $R b m 3$ putative RNA-binding protein 3, SIRT sirtuin, $\mathrm{SpO}_{2}$ peripheral oxygen saturation, VEGF vascular endothelial growth factor, $\uparrow$ indicates increase, $\downarrow$ indicates decrease

responses to thermal $\left(20\right.$ and $\left.30{ }^{\circ} \mathrm{C}\right)$ and very low $(610 \mathrm{~m})$ and moderate altitude $\left(2000 \mathrm{~m} \mathrm{FiO}_{2} \approx 0.17\right)$ over similar durations of exposure $(10 \times 60 \mathrm{~min}$ sessions $)$ and at a similar relative intensity $\left(60 \% \dot{V} \mathrm{O}_{2 \text { peak }}\right)$ [65]. Performance during a $16.1 \mathrm{~km}$ TT in hypoxic conditions $\left(\mathrm{FiO}_{2}=0.14\right.$, $\sim 3300 \mathrm{~m}$ [21]) demonstrated that while no improvements were made following control training $(+0.8 \%)$, hypoxic training $(-6.9 \%)$ and HA $(-4.8 \%)$, both improved performance without further increasing physiological strain. These data suggest $\mathrm{HA}$ is an effective alternative to hypoxic training.

Given that no change occurred in the normothermic, normoxic $\dot{V} \mathrm{O}_{2 \text { peak }}$ test post-hypoxic training or HA, it is proposed that the HA and hypoxic training facilitated an improvement in the sustainable $\dot{V} \mathrm{O}_{2}$ or $\% \dot{V} \mathrm{O}_{2 \text { peak }}$ during the $16.1 \mathrm{~km}$ TT in hypoxia. The mechanism behind this positive adaptation following $\mathrm{HA}$ or hypoxic training appears allied to the improved $\mathrm{SpO}_{2}$ that follows these interventions. Different pathways may be responsible for this improvement, with $\mathrm{HA} \quad\left(\mathrm{SpO}_{2}+2 \%\right)$ utilising 
increased PV to facilitate greater available $\dot{Q}$ and, ultimately, central $\mathrm{O}_{2}$ distribution/delivery, while hypoxic training $\left(\mathrm{SpO}_{2}+1 \%\right)$ likely elicits adaptations within the muscle that augment more efficient $\mathrm{O}_{2}$ exchange and utilisation rather than haematological adaptations that are improbable utilising this altitude training modality (see Millet et al. [12] for a review of the area). Specific experimental designs to identify the precise mechanisms underpinning these performance benefits within hypoxia are discussed in Sect. 2.1.3.

Lee et al. [66, 67] provide an insight into the necessary HA dose to elicit cross-acclimation. In the first of two experiments, Lee et al. [66] implemented an acute intervention whereby participants exercised for $90 \mathrm{~min}$ at $50 \%$ $\dot{V} \mathrm{O}_{2 \text { peak }}$ in four conditions: normothermic normoxia $\left(\mathrm{FiO}_{2}\right.$ $\left.\approx 0.21,20^{\circ} \mathrm{C}, 40 \% \mathrm{RH}\right)$, hyperthermic normoxia $\left(\mathrm{FiO}_{2}\right.$ $\left.\approx 0.21,40{ }^{\circ} \mathrm{C}, 20 \% \mathrm{RH}\right)$, normothermic hypoxia $\left(\mathrm{FiO}_{2}\right.$ $\approx 0.14$, equivalent to $\approx 3000 \mathrm{~m}, 20^{\circ} \mathrm{C}, 40 \% \mathrm{RH}$ ), or combined heat and hypoxia $\left(\mathrm{FiO}_{2} \approx 0.14,40{ }^{\circ} \mathrm{C}, 20 \% \mathrm{RH}\right)$. These interventions, performed in a randomised order, preceded a 60 min hypoxic stress test (cycling at $50 \% \dot{V} \mathrm{O}_{2 \text { peak }}$ ) in normothermic hypoxia $\left(\mathrm{FiO}_{2}=0.14\right)$. It was observed that no difference in physiological responses occurred in the subsequent hypoxic stress test ( $24 \mathrm{~h}$ post initial exposure), with the authors concluding that an acute intervention was insufficient to induce the requisite magnitude of adaptation. A follow-up experiment [67] extended understanding of responses beyond an acute exposure by extending the dose towards that of a short-term HA regime $(3 \times 60 \mathrm{~min}$ cycling at $50 \% \dot{V} \mathrm{O}_{2 \text { peak }}$ in either hot conditions, i.e. HA $\left[40{ }^{\circ} \mathrm{C}\right.$ and $20 \% \mathrm{RH}]$ or normothermic conditions $\left[20^{\circ} \mathrm{C}\right.$ and $40 \%$ $\mathrm{RH}]$ ). A greater magnitude of physiological adaptation was induced following 3 days [67] versus 1 day [66] (see Table 1). During the hypoxic stress test (cycling at $50 \%$ $\dot{V} \mathrm{O}_{2 \text { peak }}$ ), performed $24 \mathrm{~h}$ following the final HA or normothermic training session, it was observed that exercising HR decreased $\left(\sim 5 \mathrm{~b} \mathrm{~min}^{-1}\right)$ and $\mathrm{SpO}_{2}$ was elevated $(+1 \%)$ for a greater duration of the trial in the HA group versus controls. These data indicated that the HA group was more tolerant to the acute hypoxic stress than those who had performed normothermic training.

\subsubsection{Future Directions in Heat to Hypoxia Cross- Acclimation}

There is good evidence to support heat to hypoxic crossacclimation [20, 21, 23, 67]. HA-induced adaptations are likely of benefit and are proposed as an alternative, or preferred, method for eliciting adaptation for those individuals who are initially less tolerant to hypoxia, or respond poorly to repeated exposures of hypoxia (precluding hypoxic adaptation), but respond well to heat stress. The application of cross-acclimation should therefore be investigated across a spectrum of both simulated and actual altitudes. This evidence could inform practice within sporting and occupational disciplines; however, at the current time, such applications are limited due to a paucity of data from these populations, across increasing severities of hypoxia and during differing work intensities. Consequently, further mechanistic evidence is required to inform applied practice relative to the actual experiences of travelling athletes [68] and at-risk workers [69] for whom cross-acclimation may provide an alternative to traditional altitude training regimes. Incremental terrestrial (or simulated) ascents of $\sim 800 \mathrm{~m}\left(\mathrm{FiO}_{2}=0.187\right), \sim 1800 \mathrm{~m}$ $\left(\mathrm{FiO}_{2}=0.167\right)$ and $\sim 2800 \mathrm{~m}\left(\mathrm{FiO}_{2}=0.147\right)$, as utilised by others [58], are sufficiently different from one another to allow comparisons to be made experimentally, while also ecologically valid for application towards athletic and occupational cohorts. Accordingly, it is proposed that these altitudes should be tested in further cross-acclimation experiments to supplement the data described within this review at higher altitudes of $\sim 3300 \mathrm{~m}\left(\mathrm{FiO}_{2} \approx 0.14\right.$ [21]), $\sim 4200 \mathrm{~m}\left(\mathrm{FiO}_{2} \approx 0.12\right.$ [20]), and $4350 \mathrm{~m}\left(\mathrm{FiO}_{2} \approx 0.12\right.$ [22]).

In addition to determining the efficacy of cross-acclimation across ascents, the benefits should also be considered across exercise intensity domains between individuals of higher and lower aerobic capacity. Current evidence highlights the ability for HA to reduce physiological strain at rest and within the moderate- to high-intensity domain (50-65\% $\left.\dot{V} \mathrm{O}_{2 \max }[20,21]\right)$. There appears to be less evidence supporting reductions in physiological strain in the lower-intensity domains $\left(<50 \% \quad \dot{V} \mathrm{O}_{2 \max }[20]\right)$, with a likely, but currently equivocal, understanding of the benefits at performance intensities [21,22]. The magnitude of improvement in $\dot{V} \mathrm{O}_{2 \max }$ itself may [70] or may not [71] be dependent on $\mathrm{O}_{2}$ delivery, thus reducing the mechanistic appeal of cross-acclimation to increase $\dot{V} \mathrm{O}_{2 \max }$. Accordingly, HA may not improve $\dot{V} \mathrm{O}_{2 \max }$ at altitude as expansion of PV and associated increases in $\dot{Q}$ to increase $\mathrm{O}_{2}$ delivery at $\dot{V} \mathrm{O}_{2 \max }$ are less important than $\mathrm{O}_{2}$ utilisation in the mitochondria, a factor apparently unaffected by HA [27]. Calbet et al. [56] oppose PV-mediated benefits in hypoxia, since, following altitude acclimatization, acute PV expansion $(+17 \%)$ had no additional effect on maximal $\mathrm{Q}, \dot{\mathrm{V}} \mathrm{O}_{2 \max }$ and exercise capacity at high altitude $(5260 \mathrm{~m})$. These data from Calbet et al. [56] suggest cross-acclimation may be more impactful at submaximal intensities as the data describing physiological responses to altitude following the PV expansion were improved during submaximal work (120 W, 50-55\% maximum power) [56]. However, some caution should be exercised in the interpretation of these results, given that participants in the 
experiment of Calbet et al. [56] were altitude acclimatized individuals, which parallels the work of White et al. [22], who noted that the potential for cross-acclimation to influence $\dot{V} \mathrm{O}_{2 \max }$ and exercise performance may be diminished in those habituated to altitude. The magnitude of cross-acclimation that can be attributed to reduced temperature and/or PV expansion could be investigated using an experimental design whereby acute reductions in core temperature and acute PV expansion, both in isolation and combination, replicate the observed adaptive responses to HA.

Once applications allied to continuous exercise utilising primarily aerobic metabolism are better understood, the efficacy of cross-acclimation benefits during repeated and/ or intermittent sprinting may yield noteworthy applications in other disciplines of athletic performance, e.g. for team sports in which altitude elicits reductions in performance [72] of a similar magnitude to that of equivalent work in hot conditions [73]. There is also a necessity to determine timescales required to induce cross-acclimation between sexes, with females displaying a delayed temporal pattern during the attainment of HA [74]. The decay of crossacclimation is unknown; at the present time, the only evidence available is limited to that of the decay of HA in hot conditions [75]. Benefits with varying intensities and movement patterns, and the identification of any sex differences, would give further context towards understanding who may benefit from cross-acclimation.

Cross-acclimation research to date has primarily focused on cardiovascular mechanisms. Accordingly, there is a necessity to determine alterations in neuromuscular function, particularly when exercise performance is important. It has been observed that high altitude acclimatization reduces central, but not peripheral, fatigue, potentially via improved $\mathrm{CaO}_{2}$ and/or $\mathrm{PO}_{2}$ [76], and preliminary data indicate that HA may augment neuromuscular function [77]. Another area for consideration is the role of crossadaptation in mitigating the decline in cognition that occurs during exposure to environmental extremes [78], such as heat [79-81] or hypoxia [82, 83]. The seminal experiment in the field of cross-adaptation [23] observed that, following HA, the number of false positives during a visual vigilance task in hypoxia reduced $(-50 \%)$, while four choice reaction times improved $(+5.3 \%)$ compared with pre-intervention baseline. Accordingly, in addition to exploring biological responses and mechanisms resulting in cross-adaptation, experimental work determining the potential to elicit favourable changes in simple and complex cognitive tasks in hypoxia following HA (and CA) is warranted [78]; however, appropriate control groups should be included.
A final area of interest regarding the practicality of heathypoxic cross-acclimation is the use of hot-water bathing $[54,55]$, or sauna exposure $[52,53]$, to induce adaptations. These interventions are generally available to all, and, accordingly, present few barriers to their implementation and may be especially desirable when an additional exercise load is undesirable, e.g. for athletes [68]. Also desirable for athletes and workers may be the rapid induction of cross-acclimation via twice daily HA [84]. It might also be noteworthy that, since beneficial cross-acclimation adaptations are becoming more readily observed from isolated HA interventions, a combination of HA in addition to traditional hypoxic exposure might reduce the duration required to acclimate to altitude [10], or provide a greater magnitude of adaptation [65]. A discussion of the mechanisms by which heat may facilitate hypoxic adaptation can be found in Sect. 2.2.1.

\subsection{Heat to Hypoxia Cross-Tolerance}

\subsubsection{Mechanisms by Which Heat to Hypoxia Cross- Tolerance May Occur}

Cross-tolerance experimental work has identified heat shock proteins (HSP) as key components of the crossstressor response. At the current time, experimental evidence dictates that of greatest interest for cross-tolerance are HSP72 [17, 85] and HSP90 $\alpha$ [18], both of which demonstrate increases in basal levels following HA $[21,86]$ and in response to various hypoxic exposures with [21, 67] and without exercise [87-89].

First discovered in response to heat stress [90], the HSP70 family is present in two predominant isoforms: a constitutively expressed protein isoform HSC70 (HSP73), and a highly inducible 'chaperone' isoform HSP72 (HSPA1A/HSPA1B) [91]. Increases in intracellular HSP72 (iHSP72) are largely dictated by the transcription factor heat shock factor 1 (HSF1), which is translocated to the nucleus whereupon, binding to heat shock elements (HSEs), appropriate messenger RNA (mRNA) [Hsp] transcription occurs. Inhibition of HSF1 increases the susceptibility to acute in vivo thermal stress (i.e. heat stroke [92]), and similarly precludes procurement of optimal physiological adaptation to chronic thermal stress (i.e. heat-acclimated phenotype [93, 94]). Conversely, upon gene transcription via HSF1, large changes occur in the iHSP72 content of cells, notably following acute and chronic exercise [86, 95]. While numerous molecular signals are elicited in response to exercise $[96,97]$ and thermal stimuli [98], a common observation in both independent and combined heat and exercise models [86, 99, 100], and in 
independent and combined hypoxia and exercise models [87-89, 101], is the increase in HSPs [29]. Most relevant to HA-mediated cross-tolerance, it has been demonstrated that HSP72 increases in response to thermal stress [102], notably an increase deep body temperature [103], although others have also observed HSP72 protein translation as being responsive to training of a continuous or intermittent nature, whereby large changes in temperature are unlikely [104]. Exercise elicits numerous cellular and molecular stressors that, in isolation or in combination, behave as inductive stimuli for increases in HSP72 [105]. Stimuli that induce changes include, but are not limited to, whole body and local hyperthermia [106], oxidative stress/free radical formation [88, 107], substrate depletion [108], hypoxia/ischaemia [89], altered $\mathrm{pH}$ [109] and increased calcium concentration [110].

The initially identified role of HSP72 in humans was to provide cellular protection during heat stress. Emerging data have since identified that HSP72 is important in facilitating positive heat [93] and heat-independent adaptations [105] at a physiological and cellular level. HSPs facilitate maintenance of cellular and protein homeostasis, with regulatory roles in mitigating apoptosis, and facilitate recovery from and adaptation to stress [28, 111, 112]. The functional benefits of increased HSP have recently been discussed in detail elsewhere [99, 105, 113], alongside their specific roles in heat to altitude cross-tolerance [17-19]. Increases in HSP72 during subsequent heat stress improve tolerance to a hot environment by maintaining intestinal epithelial tight junction barriers $[114,115]$ by increasing resistance to gut-associated endotoxin translocation [116] and/or by reducing the systemic inflammatory response [85, 117]. These responses which ameliorate pathologies associated with heat illness [118] occur in conjunction with the induction of the HA phenotype [93]. Animal models in which transgenic overexpression of HSP72 is induced demonstrate improved markers of oxidative metabolism, e.g. mitochondrial number and function [119], although it is not known if this is a result of increased HSP72 per se, or generally increased activity levels (training) in response to the genetic modification. Should the former be observed in humans in hypoxia, this is an appealing mechanism whereby individuals due to visit altitude for training might benefit from a pre-altitude HA intervention to improve the physiological response to altitude (cross-acclimation), thus attenuating the immediate decline in training quality while also benefiting from improved adaptive capacity in response to altitude training at a cellular and molecular level (cross-tolerance).

It has been identified that both HSP72 and HSP90 increase the stability of hypoxia-inducible factor- $1 \alpha$ (HIF$1 \alpha$ ), and, in doing so, they may provide improved erythropoietic [89] and angiogenic responses [120, 121], which are of significance when training in hypoxia [122, 123]. Indeed, HSP72 has recently been identified as a specific regulator of angiogenesis [121, 124] and erythropoiesis [125, 126]. Further, as yet unexplored, benefits proposed by Ely et al. [17] are that increased HSP72 may improve endothelial barrier integrity in the cerebral and pulmonary microcirculation, thereby reducing the severity of altitude illness, with HSP90 acting as a cofactor in the production of nitric oxide synthase (NOS) to regulate vasodilatation, potentially reducing pulmonary hypertension [127]. Many of these proposed mechanisms for crosstolerance require experimental support, particularly in human studies, the underlying concept being contingent on the potential for HA to increase HSPs, with the subsequent attenuation of a response indicative of a reduced cellular stress response. Additionally, HSPs provide only one known pathway for cross-tolerance to occur; however, many others may exist and thus the focus on HSPs in isolation might be considered a limitation of current experimental work.

\subsubsection{Evidence of Heat to Hypoxia Cross-Tolerance}

Although animal models suggest the maximum cross-tolerance benefits occur after $\sim 4$-week interventions [99, 100], the necessity for prolonged ( $>10$ day) protocols identified as requisite for cross-acclimation in humans may not be true of cross-tolerance, at least in terms of providing some, if not total, cellular resistance to altitude. Lee et al. [66] observed an acute cellular preconditioning effect in response to a single prior exercise heat stress session during subsequent hypoxia. Post-exercise, monocyte HSP72 increased $+107 \%$ in normothermic normoxia $\left(\mathrm{FiO}_{2}\right.$ $\left.\approx 0.21,20{ }^{\circ} \mathrm{C}, 40 \% \mathrm{RH}\right),+153 \%$ in hyperthermic nor$\operatorname{moxia}\left(\mathrm{FiO}_{2} \approx 0.21,40{ }^{\circ} \mathrm{C}, 20 \% \mathrm{RH}\right),+126 \%$ in normothermic hypoxia $\left(\mathrm{FiO}_{2} \approx 0.14\right.$, equivalent to $\approx 3000 \mathrm{~m}$, $\left.20{ }^{\circ} \mathrm{C}, 40 \% \mathrm{RH}\right)$ and $+161 \%$ in the combined stressors of hyperthermic hypoxia $\left(\mathrm{FiO}_{2} \approx 0.14,40{ }^{\circ} \mathrm{C}, 20 \% \mathrm{RH}\right)$. The greater increase in the two hyperthermic conditions reflected the importance of larger, sustained changes in core temperature for HSP72 gene transcription [103]. The elevation was transient following normothermic normoxia, with a return towards resting values $24 \mathrm{~h}$ after the acute bout. However, the elevations remained $24 \mathrm{~h}$ after hyperthermic normoxia $(+130 \%)$, normothermic hypoxia $(+118 \%)$ and combined hyperthermic hypoxia $(+131 \%)$. A reduced monocyte HSP72 induction during the hypoxic stress test following hyperthermic normoxia, normothermic hypoxia and hyperthermic hypoxia indicated that cellular tolerance to hypoxia had been conferred via the increased environmental-specific stress in the absence of reduced physiological strain. Exercise in normothermic normoxia was not sufficient to induce increases in HSP72. 
A follow-up experiment extended the acute preconditioning response into a 3-day HA regime [67]. The initial hypoxic stress test elicited an equal increase in monocyte HSP72 between groups (controls $+34 \%$; HA $+39 \%$ ). As a result of the increased physiological stress of HA, basal HSP72 increased $(+28 \%)$ following the 3-day intervention, but remained unchanged in the control group $(+3 \%)$. In line with the hypoxic stress test that followed the acute intervention of Lee et al. [66], the control group demonstrated a monocyte HSP72 increase $(+48 \%)$, suggesting cellular protection against the hypoxic stress was insufficient. In contrast, HA attenuated the previously increased monocyte HSP72 expression, demonstrating that a protective effect from HA-derived HSP72 was ameliorating the signal to increase HSP transcription and translation in hypoxia, thus inducing cross-tolerance [67].

Similar responses to that of the monocyte protein $[66,67]$ were observed, by Gibson et al. [20], in leukocyte Hsp72 mRNA in response to hypoxia (Table 2). In this experiment, where, during a 30 min hypoxic stress test $\left(\mathrm{FiO}_{2}=0.12\right)$ consisting of a $10 \mathrm{~min}$ rest followed by $2 \times 10 \mathrm{~min}$ bouts of exercise at $40 \%$ and $65 \% \dot{V} \mathrm{O}_{2 \max }$, $\mathrm{HA}$ but not normothermic training mitigated the hypoxia-induced increase in $\mathrm{Hsp} 72$ mRNA (pre-HA $+37 \%$, post-HA $-5 \%$ ), but not leukocyte $H s p 90 \alpha$ mRNA (pre-HA $+23 \%$, post-HA $+14 \%$ ) that had previously occurred during the hypoxic stress test performed prior to HA. This was a comparable direction of response to that of McClung et al. [86] in peripheral blood mononuclear cells undergoing a post-HA ex vivo thermal incubation for HSP72 (pre-HA +3.3-fold, post-HA +2.2-fold). However, McClung et al. [86] observed an attenuation in HSP90 $\alpha$ (pre$\mathrm{HA}+87 \%$, post-HA no change from basal) not evidenced by Gibson et al. [20] during in vivo hypoxia. In addition to crossacclimation and improved performance data, Lee et al. [21] observed that improved cellular tolerance to hypoxia was equally attainable utilising either HA or hypoxic training. Resting monocyte HSP72 increased in response to HA $(+62 \%)$ and hypoxic training $(+58 \%)$ to a similar extent, but was unchanged after thermoneutral, normoxic control training (+9\%). Increased HSP72 following HA and hypoxic training led to an attenuated HSP72 response to hypoxic exercise in 40 min hypoxic stress tests $\left(50 \% \dot{\mathrm{V}} \mathrm{O}_{2 \text { peak; }} 18{ }^{\circ} \mathrm{C}, 35 \% \mathrm{RH}\right.$ $\left.\mathrm{FiO}_{2}=0.14\right)$. This response was comparable in direction, i.e. HA provided cross-tolerance to hypoxic stress (Table 2), but of a greater magnitude of response to that observed using a 10-day [21], rather than a 3-day, HA intervention in identical conditions [67]. These data emphasise that while acute [66] and short-term [67] cross-tolerance benefits are attainable, a dose response is apparent. The work of Gibson et al. [20], and Lee et al. [21, 66, 67] highlight that increased HSP72 attained during HA provides sufficient cellular protection to mitigate further increases in the protein in subsequent hypoxia.

Table 2 Heat to hypoxia cross-tolerance experimental data

\begin{tabular}{|c|c|c|c|c|}
\hline $\begin{array}{l}\text { Study, } \\
\text { year }\end{array}$ & $\begin{array}{l}\text { Heat acclimation } \\
\text { protocol }\end{array}$ & Adaptations to heat acclimation & Hypoxic protocol & $\begin{array}{l}\text { Improved responses to } \\
\text { hypoxia }\end{array}$ \\
\hline $\begin{array}{l}\text { Lee et al. } \\
\text { [66], } \\
2014\end{array}$ & $\begin{array}{l}3 \text { days } \\
75 \text { min day } \\
\text { (including } 15 \mathrm{~min} \\
\text { preliminary rest) } \\
40{ }^{\circ} \mathrm{C} 20 \% \mathrm{RH} \\
\text { [Fixed] Cycling @ } \\
50 \% \dot{V} \mathrm{O}_{2 \text { peak }}\end{array}$ & $\begin{array}{l}\uparrow \text { Basal monocyte HSP72 } \\
\uparrow \mathrm{eHsp} 72 \text { pre/post session }\end{array}$ & $\begin{array}{l}15 \text { min @ rest } \\
60 \min @ 50 \% \dot{V} \mathrm{O}_{2 \text { peak }} \\
\left(\mathrm{FiO}_{2}=0.14 ; \sim 3300 \mathrm{~m}\right)\end{array}$ & $\begin{array}{l}\text { Monocyte HSP72 increase } \\
\text { attenuated after heat } \\
\text { acclimation } \\
\uparrow \text { eHSP72 maintained after } \\
\text { heat acclimation }\end{array}$ \\
\hline $\begin{array}{l}\text { Gibson } \\
\text { et al. } \\
{[20] \text {, }} \\
2015\end{array}$ & $\begin{array}{l}10 \text { days } \\
90 \text { min day }{ }^{-1} \\
40{ }^{\circ} \mathrm{C} 40 \% \mathrm{RH} \\
{[\mathrm{ISO}] \text { Cycling @ } 65 \%} \\
\dot{V} \mathrm{O}_{2 \text { peak }}\end{array}$ & $\begin{array}{l}\uparrow H s p 72 \text { mRNA pre/post session } \\
\uparrow H s p 90 \alpha \text { mRNA pre/post session }\end{array}$ & $\begin{array}{l}10 \text { min rest } \\
10 \text { min cycling @ } 40 \% \dot{V} \mathrm{O}_{2 \text { peak }} \\
10 \text { min cycling @ } 65 \% \dot{V} \mathrm{O}_{2 \text { peak }} \\
\left(\mathrm{FiO}_{2}=0.12 ; \sim 4500 \mathrm{~m}\right)\end{array}$ & $\begin{array}{l}\text { Attenuated } H s p 72 \text { mRNA } \\
\text { increase after heat } \\
\text { acclimation } \\
\uparrow H s p 90 \alpha \text { mRNA } \\
\text { maintained after heat } \\
\text { acclimation }\end{array}$ \\
\hline $\begin{array}{l}\text { Lee et al. } \\
\text { [21], } \\
2016\end{array}$ & $\begin{array}{l}10 \text { days } \\
75 \text { min day }{ }^{-1} \\
\text { (including } 15 \text { min } \\
\text { rest) } \\
40{ }^{\circ} \mathrm{C} 25 \% \mathrm{RH} \\
\text { [Fixed] Cycling @ } \\
50 \% \dot{V} \mathrm{O}_{2 \text { peak }}\end{array}$ & $\begin{array}{l}\uparrow \text { Basal monocyte HSP72 (comparable } \\
\text { magnitude to equivalent training in } \\
\text { hypoxia) }\end{array}$ & $\begin{array}{l}40 \text { min @ } 50 \% \dot{V} \mathrm{O}_{2 \text { peak }} \text { then } \\
16.1 \mathrm{~km} \text { cycling TT } \\
\left(\mathrm{FiO}_{2}=0.14 ; \sim 3300 \mathrm{~m}\right)\end{array}$ & $\begin{array}{l}\text { Monocyte HSP72 increase } \\
\text { attenuated after heat } \\
\text { acclimation }\end{array}$ \\
\hline
\end{tabular}

[Fixed] denotes fixed-intensity protocol, [ISO] denotes isothermic/controlled hyperthermia protocol, $\mathrm{FiO}_{2}$ fractional inspired oxygen content, $H S P 72 / H s p 72$ heat shock protein-72 (eHSP extracellular protein, HSP intracellular protein, $H s p$ gene). $H s p 90 \alpha$ heat shock protein-90 $\alpha, m R N A$ messenger RNA, $R H$ relative humidity, $T T$ time trial, $\dot{V} O_{2 p e a k}$ peak oxygen uptake, $\uparrow$ indicates increase 


\subsubsection{Future Directions in Heat to Hypoxia Cross- Tolerance}

In vivo, human experiments should further consider the kinetics of cross-tolerance in response to HA over varying timescales [51, 63], isolating the independent effects of exercise stimuli and environmental stimuli [103], and implementing post-intervention testing in hypoxic conditions using fixed absolute and fixed relative intensity prescriptions. Some presented experimental work does not include a post-intervention determination of $\dot{V} \mathrm{O}_{2 \max }$, e.g. Gibson et al. [20], and therefore it cannot be determined whether attenuated HSP responses are a result of a reduced relative intensity or whether the physiological and cellular adaptations induced by HA mitigated the hypoxic response. Future work should acknowledge this potential limitation.

The efficacy of cross-tolerance could be supported by a number of experimental designs utilising intracellular HSPs derived from a range of tissue sites allied to the specific function under investigation. From a mechanistic perspective, experimental work using hypoxic cell culture work similar to that where thermal incubation was performed [86] appears warranted to determine, in a well-controlled ex vivo environment, the time course/kinetics of cross-tolerance, either on a day-by-day [89] or pre/post HA basis [63]. Such ex vivo cell culture analysis would yield novel and important data regarding the capacity of cross-tolerance to induce cytoprotective cellular adaptation. The benefits of this research paradigm are mechanistic and well-controlled, yet they should be complemented by further in vivo analysis to offer a more ecologically valid understanding.

To clearly determine independent roles played by increased HSP in the development of cross-tolerance, manipulation of the intracellular protein content is likely required. Quercetin, a plant flavonol and an antioxidant, has been demonstrated as effective in attenuating increases in basal and inducible HSP72 during HA [93], while clinical trials and animal models support the use of the $\alpha$-amino acid glutamine [115] or O-(3-piperidino2-hydroxy-1-propyl) nicotinic amidoxime (BGP-15) as an HSP72 co-inducer [128]. These pharmacological interventions attenuate and elevate HSP72, respectively, providing an opportunity to isolate the independent effects of physiological and cellular adaptations in cross-tolerance/acclimation. These manipulations also facilitate the opportunity to explore specific benefits of cross-tolerance. This is pertinent as the precise benefits of the cross-tolerance-mediated reduction in HSP currently lack context, and experimental support for the effects of a reduced disruption to cellular homeostasis in subsequent hypoxia is unavailable.

It remains unknown what the minimum increase in HSPs relevant to elicit cytoprotection is. This is likely dependent on the nature of the stress presented; thus, for each of the described benefits, the necessary dose of HSP must be identified to determine which timescale of HA to apply. From a practical rather than mechanistic perspective, in spite of differences in the temporal patterning of HA which has implications for cross-acclimation [74], it appears that the transcription of HSP72 does not differ between sexes during HA [129]; however, translation into elevated basal protein, at least during normothermic training, may be inhibited in females [130]. Should the latter be further evidenced in an HA model, this presents limitations for cross-tolerance in females, with implications for female athletes or occupational workers due to experience an altitude sojourn. A final unknown consideration relates to the application of HA to individuals experiencing conditions akin to anoxia, such as free divers [131], who may additionally benefit from both cardiovascular and cellular adaptation [132-136].

\section{Cold to Hypoxia Cross-Adaptation}

\subsection{Mechanisms by Which Cold to Hypoxia Cross- Adaptation May Occur}

Data supporting the benefits of cold adaptations and subsequent improvements in the physiological responses to altitude are sparse. Indeed, to the authors' knowledge, only one experiment testing this phenomenon in humans has been published to date [25]. A rationale for this paucity of data, beyond the acknowledgement that the area of crossadaptation is in its infancy, is the limited number and magnitude of reported physiological adaptations in response to cold stress that are likely impactful at altitude. As discussed in Sect. 2.1.1, adaptations to heat stress have direct implications for exercise in hypoxia due to favourable maintenance of, or increases in, $\dot{Q}$. Increased $\dot{Q}$ is beneficial in hypoxia by offsetting reductions in $\mathrm{PO}_{2}$ and improving $\mathrm{CaO}_{2}$ at the desired organ. During cold stress, $\dot{Q}$ is not compromised, Accordingly, adaptations allied to this mechanism to defend blood pressure and blood $/ \mathrm{O}_{2}$ distribution are not made following CA. Instead, following exposure to acute cold stress, a rapid sympathetic systemic response is initiated to defend body temperature, notably via vasoconstriction, and alterations in metabolism. This response is less prevalent during exercise in the cold [137]. It is known that exposure to cold [138] and altitude [11] increases circulating catecholamines, and this hormonal response has metabolic implications, notably those allied to glycolysis. Thus, the attenuation of this response with repeated cold [139] or prolonged hypoxia [140] may be a beneficial cold to hypoxic cross-acclimation adaptation. 
Cold adaptation can be divided into habituation, metabolic adaptation, and insulative adaptation [8]. Habituation is characterized by physiological changes induced following repeated cold exposures whereby the magnitude of response to subsequent stress is attenuated compared with the pre-exposure state. Within habituation, metabolic adaptation is characterised by a reduction in stress-induced increases in thermogenesis. Metabolic defence of body temperature is initially facilitated by shivering thermogenesis to increase metabolic heat production [141], with non-shivering thermogenesis occurring later via metabolism of brown adipose tissue [142]. The latter (non-shivering) contributes to a lesser degree than the former (shivering thermogenesis) [8]. Insulative adaptation is characterized by enhancing mechanisms that conserve body heat [143, 144], notably reducing thermal conductance at the skin to the environment via vasoconstriction. Metabolic adaptations to CA can be achieved in similar time frames to HA interventions ( 5-14 days [8]); however, the utilisation of short-term CA protocols fails to elicit markers of insulative adaptation [145, 146]. Extensive protocols (90 min, $18{ }^{\circ} \mathrm{C}$ exposures, 5 days week ${ }^{-1}, 8$ weeks) are required to induce changes in this pathway for temperature defence [143, 144]. Accordingly, given the lack of cross-acclimation benefits (excluding cases of combined altitude and cold), and the prolonged duration required to elicit meaningful adaptation, the remainder of this section will focus on metabolic adaptations, driven by changes in autonomic activation to repeated cold stress, and the beneficial evidence for this cross-acclimation pathway in hypoxia.

Increased metabolic rates on exposure to acute cold stress attenuates with repeated exposures [137]. This has been demonstrated as occurring after single [147] and repeated exposures at rest [148], with improvements in exercise economy, i.e. reduced $\dot{V} \mathrm{O}_{2}$ and reduced RER attainable in the cold [149]. The optimal number of sessions for metabolic inhibition to passive cold stress is approximately six coldwater immersions $\left(14{ }^{\circ} \mathrm{C}\right.$ until core temperature $\left.=35.5^{\circ} \mathrm{C}\right)$ where an $\sim 2 \mathrm{~mL} \mathrm{~kg}^{-1} \min ^{-1}$ reduction in $\dot{V} \mathrm{O}_{2}$ was observed, although significant reductions in metabolism may be obtained after two immersion days [148]. Regrettably, no data have been published evidencing changes in substrate utilisation, e.g. a reduced RER, with metabolic CA. A reduced RER, indicative of preferential fat oxidation, is an appealing cross-acclimation mechanism whereby, in addition to reductions in total energy expenditure at altitude following CA, reduced energy derived from carbohydrate would potentially spare this substrate for exercise performance.

\subsection{Evidence of Cold to Hypoxia Cross-Adaptation}

Evidence for the transfer of autonomic and subsequent metabolic adaptations in response to repeated cold-water immersions to hypoxia in humans is limited to one experiment [25]. Lunt et al. [25] observed that $6 \times 5$ min immersions in cold $\left(12{ }^{\circ} \mathrm{C}\right)$ versus thermoneutral $\left(35^{\circ} \mathrm{C}\right)$ water (twice daily over 3 days) reduced the sympathetic response to a 10 min bout of cycling at $100 \mathrm{~W}$ breathing hypoxic gas $\left(\mathrm{FiO}_{2}=0.12\right)$. Reduced catecholamine (adrenaline and noradrenaline) responses followed the cold, but not the thermoneutral, intervention, indicating the sympathetic response to hypoxia had been attenuated. At a physiological level, this autonomic inhibition elicited reduced HR $\left(-8 \mathrm{~b} \mathrm{~min}^{-1}\right)$ and HR variability, as well as breathing rate $\left(-5\right.$ br $\left.\min ^{-1}\right)$, and, while tidal volume increased $(+0.3 \mathrm{~L})$, minute ventilation decreased $\left(-3.7 \mathrm{~L} \mathrm{~min}^{-1}\right)$. A reduction in $\dot{V} \mathrm{O}_{2}\left(-0.1 \mathrm{~L} \mathrm{~min}^{-1}\right)$, compared with the thermoneutral group, was observed, and reductions in hyperventilation reduced carbon dioxide production $\left(\dot{V} \mathrm{CO}_{2} ;-0.5 \mathrm{~L} \mathrm{~min}^{-1}\right)$ and resulted in a reduction in RER $(-0.1)$ (see Fig. 1). These metabolic responses are beneficial for those travelling to altitude, given that classical responses to hypoxia include increased ventilation, energy expenditure, and preferential use of glycogen [11]. The populations who would derive the greatest benefits would be those performing prolonged aerobic work at altitude [150], i.e. in a similar exercise-intensity domain, albeit for longer durations, to that experimentally investigated by Lunt et al. [25]. In addition to physiological adaptations, subjective responses to hypoxia also improved following cold-water immersion ( -2 symptoms; -5 cumulative symptom severity). This observation, supported by data evidencing cognitive task improvements following a repeated cold-water immersion of a similar duration to that of HA [151], may be important when the performance of cognitive tasks at altitude is necessary.

\subsection{Future Directions in Cold to Hypoxia Cross- Adaptation and Cross-Tolerance}

Given evidence that cold to hypoxic cross-adaptive pathways are primarily effective at reducing the sympathetic response to the environmental stimuli, the rapid attainment of this phenotype warrants future investigation. A multiexposure, within-day series of cold treatments may accelerate the desensitisation of the autonomic and metabolic responses to the stress, a process that is not as time-dependent as adaptive processes congruent with $\mathrm{HA}$ or insulative $\mathrm{CA}$, and which likely confers minimal benefits in hypoxia. The work of Lunt et al. [25] provides experimental evidence for the efficacy of cross-acclimation in a low- to moderate-intensity domain. It remains unknown whether this extends to increasing exercise intensities, including those that characterise athletic performance, or during chronic hypoxia. As with HA, the decay of CA into cross-acclimation is unknown; however, data suggest the 
effects of CA (two 3-min head-out immersions in water of $10{ }^{\circ} \mathrm{C}, 4$ days apart) may last 14 months, which has clear appeal to those requiring intervention [152]. Animal models provide supporting data for the autonomic and metabolic pathways for future human study in the area (see Chauhan et al. [153] for a review).

Cold cross-tolerance in humans is a novel area in which, to the authors' knowledge, no human experimental work has been published. Accordingly, the role of 'cold shock proteins' and HSPs in response to CA remains a novel area for future investigation in humans despite similar cross-tolerance response genes, e.g. HSPs and sirtuins 1-4, in mammals [98] and fish [154]. Of interest are coldinduced RNA binding protein (CIRP) and RNA-binding motif protein $3(\mathrm{Rbm} 3)$, which respond to both cold and hypoxia [155]. This cellular response may serve a novel cross-tolerance role in hypoxia, given that data identifying increases in the aforementioned cold shock proteins are consistent with associated reduced cellular damage during hypoxic or cold stress $[156,157]$.

Short cold-air exposures also increase HSP72 expression compared with an equivalent thermoneutral control [158]. Accordingly, it is likely HSP72 expression is increased during/following repeated cold-water immersions. Mechanistically, this may not result from the cold per se, but be mediated by the indirect action of catecholamines on HSE and HSF1 [159], a mechanism to be further investigated.

Cold exposure, most effectively implemented via coldwater immersion, provides a simple and expedient method to improve physiological responses to hypoxia in populations such as athletes and occupational groups. The use of cold-water immersion e.g. 'ice bathing' is widespread in the athletic performance-recovery domain [160], indicating that the intervention is feasible for many sporting, and indeed occupational, applications. Caution should be exercised in those with contraindications to cold exposure and in those wishing to increase training status. While the risks to health following cold exposure are well-established for some [161], it has been shown that cold-water immersion post continuous or intermittent exercise is beneficial, acutely [162, 163] and with repeated use [164], with benefits linked to reduced body temperatures, consequently ameliorated central nervous system-mediated fatigue, and by reducing cardiovascular strain with enhanced parasympathetic activation [165]. Accordingly, a future research direction should investigate normal, scheduled training in the morning with subsequent cold exposures in the late afternoon or evening once recovery from the exercise has largely been facilitated. This method has potential additional benefits of improving sleep quality [166] and providing a reduction in thermal strain during ensuing exercise bouts [167], with some data showing that cold-water immersion following high-intensity interval training in the heat is able to further increase gene transcripts allied to mitochondrial biogenesis and the HSP response [168]. There is potential for cold-water immersions to 'blunt' training adaptation, however this appears more relevant to resistance training paradigms [169, 170], when implemented immediately post-exercise [171], a modality that is highly unlikely to be used for crossadaptation. It is useful that the heat-hypoxia and cold-hypoxia cross-acclimation pathways are different. To induce the maximal cross-adaptive effect, it is further proposed that morning HA could be supplemented with evening cold-water immersion to elicit favourable cardiovascular, thermoregulatory, metabolic and cellular cross-adaptive responses; however, this proposition requires experimental elucidation to confirm our hypothesis.

\section{Conclusions}

This review has highlighted the physiological and cellular (HSP) adaptations that can be induced using HA or CA to attenuate the disruptions to homeostasis upon exposure to hypoxia-inducing conditions. Although in its infancy, experimental data in the field should encourage further investigation of the benefits of cardiovascular and thermoregulatory adaptations via HA, and metabolic adaptations via CA, as cross-acclimation pathways effective across a spectrum of exercise intensities at various altitudes. Cross-tolerance via increased HSPs requires significant further investigation implementing well-controlled in vivo and ex vivo experimentation whereby the precise effects of accumulated basal HSPs on the specific negative effects of hypoxic stress and altitude illness are determined. Finally, once the precise mechanisms for cross-adaptation are identified, refinements to the methods implemented for each intervention should be made to optimise their use.

\section{Compliance with Ethical Standards}

Funding No sources of funding were used to assist in the preparation of this review.

Conflict of interest Oliver Gibson, Lee Taylor, Peter Watt and Neil Maxwell declare that they have no conflicts of interest relevant to the content of this review.

Open Access This article is distributed under the terms of the Creative Commons Attribution 4.0 International License (http:// creativecommons.org/licenses/by/4.0/), which permits unrestricted use, distribution, and reproduction in any medium, provided you give appropriate credit to the original author(s) and the source, provide a link to the Creative Commons license, and indicate if changes were made. 


\section{References}

1. Haldane JS. The influence of high air temperatures. J Hyg (Lond). 1905;5:494-513.

2. Shelley WB, Horvath SM. Acclimatization of men to high temperatures. Fed Proc. 1946;5:94.

3. Horvath SM, Freedman A, Golden H. Acclimatization to extreme cold. Am J Physiol. 1947;150:99-108.

4. Barcroft J, Verzár F. The effect of exposure to cold on the pulse rate and respiration of man. J Physiol. 1931;71:373-80.

5. Sewall H. Altitude in fact and fancy. Trans Am Climatol Assoc. 1902;18:186-95.

6. Hewett FC. On the influence of altitude and pressure on the "vital capacity" of man. BMJ. 1875;2:667.

7. Sawka MN, Leon LR, Montain SJ, et al. Integrated physiological mechanisms of exercise performance, adaptation, and maladaptation to heat stress. Compr Physiol. 2011;1:1883-928.

8. Castellani JW, Young AJ. Human physiological responses to cold exposure: acute responses and acclimatization to prolonged exposure. Auton Neurosci. 2016;196:63-74.

9. Bärtsch P, Gibbs JSR. Effect of altitude on the heart and the lungs. Circulation. 2007;116:2191-202.

10. Tipton M. A case for combined environmental stressor studies. Extrem Physiol Med. 2012;1:7.

11. Bailey DM, Davies B. Physiological implications of altitude training for endurance performance at sea level: a review. Br J Sports Med. 1997;31:183-90.

12. Millet G, Roels B, Schmitt L, et al. Combining hypoxic methods for peak performance. Sports Med. 2010;40:1-25.

13. Wilber R. Application of altitude/hypoxic training by elite athletes. Med Sci Sports Exerc. 2007;39:1610-24.

14. Friedmann-Bette B. Classical altitude training. Scand J Med Sci Sports. 2008;18(Suppl 1):11-20.

15. Fudge BW, Pringle JSM, Maxwell NS, et al. Altitude training for elite endurance performance: a 2012 update. Curr Sports Med Rep. 2012;11:148-54.

16. Corbett J, Neal RA, Lunt HC, et al. Adaptation to heat and exercise performance under cooler conditions: a new hot topic. Sports Med. 2014;44:1323-31.

17. Ely BR, Lovering AT, Horowitz M, et al. Heat acclimation and cross tolerance to hypoxia: bridging the gap between cellular and systemic responses. Temperature. 2014;1:107-14.

18. Salgado RM, White AC, Schneider SM, et al. A novel mechanism for cross-adaptation between heat and altitude acclimation: the role of heat shock protein 90. Physiol J. 2014;2014:1-12.

19. White AC, Salgado RM, Schneider S, et al. Does heat acclimation improve exercise capacity at altitude? A cross-tolerance model. Int J Sports Med. 2014;35:975-81.

20. Gibson OR, Turner G, Tuttle JA, et al. Heat acclimation attenuates physiological strain and the HSP72, but not HSP90 $\alpha$, mRNA response to acute normobaric hypoxia. J Appl Physiol. 2015;119:889-99.

21. Lee BJ, Miller A, James RS, et al. Cross acclimation between heat and hypoxia: Heat acclimation improves cellular tolerance and exercise performance in acute normobaric hypoxia. Front Physiol. 2016;7:78.

22. White AC, Salgado RM, Astorino TA, et al. The effect of ten days of heat acclimation on exercise performance in acute hypobaric hypoxia (4350 m). Temperature. 2016;3:176-85.

23. Heled Y, Peled A, Yanovich R, et al. Heat acclimation and performance in hypoxic conditions. Aviat Space Environ Med. 2012;83:649-53.

24. Daanen HAM, Van Marken Lichtenbelt WD. Human whole body cold adaptation. Temperature. 2016;3:104-18.
25. Lunt HC, Barwood MJ, Corbett J, et al. "Cross-adaptation": habituation to short repeated cold-water immersions affects the response to acute hypoxia in humans. $\mathbf{J}$ Physiol. 2010;588:3605-13.

26. International Union of Physiological Sciences. Glossary of terms for thermal physiology. Second edition. Revised by The Commission for Thermal Physiology of the International Union of Physiological Sciences (IUPS Thermal Commission). Pflügers Arch Eur J Physiol. 1987;410:567-87.

27. Taylor NAS. Human heat adaptation. Compr Physiol. 2014;4:325-65.

28. Moseley PL. Heat shock proteins and heat adaptation of the whole organism. J Appl Physiol. 1997;83:1413-7.

29. Kregel KC. Heat shock proteins: modifying factors in physiological stress responses and acquired thermotolerance. J Appl Physiol. 2002;92:2177-86.

30. Charkoudian N. Mechanisms and modifiers of reflex induced cutaneous vasodilation and vasoconstriction in humans. J Appl Physiol. 2010;109:1221-8.

31. González-Alonso J, Calbet JA, Nielsen B. Metabolic and thermodynamic responses to dehydration-induced reductions in muscle blood flow in exercising humans. J Physiol. 1999;520(Pt 2):577-89.

32. González-Alonso J, Crandall CG, Johnson JM. The cardiovascular challenge of exercising in the heat. $\mathrm{J}$ Physiol. 2008;586:45-53.

33. González-Alonso J. Human thermoregulation and the cardiovascular system. Exp Physiol. 2012;97:340-6.

34. Convertino VA, Greenleaf JE, Bernauer EM. Role of thermal and exercise factors in the mechanism of hypervolemia. J Appl Physiol. 1980;48:657-64.

35. Nielsen B, Hales JR, Strange S, et al. Human circulatory and thermoregulatory adaptations with heat acclimation and exercise in a hot, dry environment. J Physiol. 1993;460:467-85.

36. Horowitz M, Shimoni Y, Parnes S, et al. Heat acclimation: cardiac performance of isolated rat heart. J Appl Physiol. 1986;60:9-13.

37. Lorenzo S, Minson CT. Heat acclimation improves cutaneous vascular function and sweating in trained cyclists. J Appl Physiol. 2010;109:1736-43.

38. Patterson MJ, Stocks JM, Taylor NAS. Humid heat acclimation does not elicit a preferential sweat redistribution toward the limbs. Am J Physiol Regul Integr Comp Physiol. 2004;286:R512-8.

39. Périard JD, Racinais S, Sawka MN. Adaptations and mechanisms of human heat acclimation: applications for competitive athletes and sports. Scand J Med Sci Sports. 2015;25:20-38.

40. Tyler CJ, Reeve T, Hodges GJ, et al. The effects of heat adaptation on physiology, perception and exercise performance in the heat: a meta-analysis. Sports Med. 2016;46(11):1699-724.

41. Legates DR, Willmott CJ. Mean seasonal and spatial variability in global surface air temperature. Theor Appl Climatol. 1990;41:11-21.

42. Webb P. Human thermal tolerance and protective clothing. Ann NY Acad Sci. 1959;82:714-23.

43. Minson CT, Cotter JD. CrossTalk proposal: heat acclimatization does improve performance in a cool condition. J Physiol. 2015;594:241-3.

44. Minson CT, Cotter JD. Rebuttal by Christopher T. Minson and James D. Cotter. J Physiol. 2015;594:249.

45. Nybo L, Lundby C. Rebuttal by Lars Nybo and Carsten Lundby. J Physiol. 2015;594:251.

46. Nybo L, Lundby C. CrossTalk opposing view: heat acclimatization does not improve exercise performance in a cool condition. J Physiol. 2015;594:245-7.

47. Karlsen A, Racinais S, Jensen MV, et al. Heat acclimatization does not improve $V \mathrm{O}_{2 \max }$ or cycling performance in a cool 
climate in trained cyclists. Scand J Med Sci Sports. 2015;25:269-76.

48. Keiser S, Flück D, Hüppin F, et al. Heat training increases exercise capacity in hot but not in temperate conditions: a mechanistic counter-balanced cross-over study. Am J Physiol Heart Circ Physiol. 2015;309:750-61.

49. Lorenzo S, Halliwill JR, Sawka MN, et al. Heat acclimation improves exercise performance. J Appl Physiol. 2010;109: 1140-7.

50. Neal RA, Corbett J, Massey HC, et al. Effect of short-term heat acclimation with permissive dehydration on thermoregulation and temperate exercise performance. Scand J Med Sci Sports. 2015;26:875-84.

51. Gibson OR, Mee JA, Tuttle JA, et al. Isothermic and fixed intensity heat acclimation methods induce similar heat adaptation following short and long-term timescales. J Therm Biol. 2015;49-50:55-65.

52. Scoon GSM, Hopkins WG, Mayhew S, et al. Effect of postexercise sauna bathing on the endurance performance of competitive male runners. J Sci Med Sport. 2007;10:259-62.

53. Stanley J, Halliday A, D'Auria S, et al. Effect of sauna-based heat acclimation on plasma volume and heart rate variability. Eur J Appl Physiol. 2015;115:785-94.

54. Zurawlew MJ, Walsh NP, Fortes MB, et al. Post-exercise hot water immersion induces heat acclimation and improves endurance exercise performance in the heat. Scand J Med Sci Sports. 2015;26:745-54.

55. Ruddock AD, Thompson SW, Hudson SA, et al. Combined active and passive heat exposure induced heat acclimation in a soccer referee before 2014 FIFA World Cup. Springerplus. 2016;5:617.

56. Calbet JAL, Rådegran G, Boushel R, et al. Plasma volume expansion does not increase maximal cardiac output or $V \mathrm{O}_{2 \max }$ in lowlanders acclimatized to altitude. Am J Physiol Heart Circ Physiol. 2004;287:1214-24.

57. González-Alonso J, Calbet JA, Nielsen B. Muscle blood flow is reduced with dehydration during prolonged exercise in humans. J Physiol. 1998;513:895-905.

58. Wehrlin JP, Hallén J. Linear decrease in $V \mathrm{O}_{2 \max }$ and performance with increasing altitude in endurance athletes. Eur J Appl Physiol. 2006;96:404-12.

59. Van Thienen R, Hespel P. Enhanced muscular oxygen extraction in athletes exaggerates hypoxemia during exercise in hypoxia. J Appl Physiol. 2015;120:351-61.

60. Powers SK, Lawler J, Dempsey JA, et al. Effects of incomplete pulmonary gas exchange on $V \mathrm{O}_{2 \max }$. J Appl Physiol. 1989;66: 2491-5.

61. Trangmar SJ, Chiesa ST, Stock CG, et al. Dehydration affects cerebral blood flow but not its metabolic rate for oxygen during maximal exercise in trained humans. J Physiol. 2014;592: $3143-60$.

62. Trangmar SJ, Chiesa ST, Llodio I, et al. Dehydration accelerates reductions in cerebral blood flow during prolonged exercise in the heat without compromising brain metabolism. Am J Physiol Heart Circ Physiol. 2015;309:1598-607.

63. Gibson OR, Mee JA, Taylor L, et al. Isothermic and fixedintensity heat acclimation methods elicit equal increases in Hsp72 mRNA. Scand J Med Sci Sports. 2015;25:259-68.

64. Dempsey JA, Hanson PG, Henderson KS. Exercise-induced arterial hypoxaemia in healthy human subjects at sea level. J Physiol. 1984;355:161-75.

65. Takeno Y, Kamijo YI, Nose H. Thermoregulatory and aerobic changes after endurance training in a hypobaric hypoxic and warm environment. J Appl Physiol. 2001;91:1520-8.

66. Lee BJ, Emery-Sinclair EL, Mackenzie RW, et al. The impact of submaximal exercise during heat and/or hypoxia on the cardiovascular and monocyte HSP72 responses to subsequent (post 24 h) exercise in hypoxia. Extrem Physiol Med. 2014;3:15.

67. Lee BJ, Mackenzie RWA, Cox V, et al. Human monocyte heat shock protein 72 responses to acute hypoxic exercise after 3 days of exercise heat acclimation. Biomed Res Int 2014;72:1-16.

68. Casadio JR, Kilding AE, Cotter JD, et al. From lab to real world: heat acclimation considerations for elite athletes. Sport Med. 2016. doi:10.1007/s40279-016-0668-9.

69. Yamazaki F. Effectiveness of exercise-heat acclimation for preventing heat illness in the workplace. J UOEH. 2013;35:183-92.

70. Gifford JR, Garten RS, Nelson AD, et al. Symmorphosis and skeletal muscle $\dot{V} \mathrm{O}_{2 \max }$ : in vivo and in vitro measures reveal differing constraints in the exercise-trained and untrained human. J Physiol. 2016;594:1741-51.

71. van der Zwaard S, de Ruiter JC, Noordhof DA, et al. Maximal oxygen uptake is proportional to muscle fiber oxidative capacity - from chronic heart failure patients to professional cyclists. J Appl Physiol. 2016;121:636-45.

72. Billaut F, Aughey RJ. Update in the understanding of altitudeinduced limitations to performance in team-sport athletes. Br J Sports Med. 2013;47(Suppl 1):i22-5.

73. Aldous JWF, Chrismas BCR, Akubat I, et al. Hot and hypoxic environments inhibit simulated soccer performance and exacerbate performance decrements when combined. Front Physiol. 2015;6:421.

74. Mee JA, Gibson OR, Doust JJH, et al. A comparison of males and females' temporal patterning to short- and long-term heat acclimation. Scand J Med Sci Sports. 2015;25:250-8.

75. Daanen HAM, Jonkman AG, Layden JD, et al. Optimising the acquisition and retention of heat acclimation. Int J Sports Med. 2011;32:822-8.

76. Amann M, Goodall S, Twomey R, et al. AltitudeOmics: on the consequences of high-altitude acclimatization for the development of fatigue during locomotor exercise in humans. J Appl Physiol. 2013;115:634-42.

77. Wingfield GL, Gale R, Minett GM, et al. The effect of high versus low intensity heat acclimation on performance and neuromuscular responses. J Therm Biol. 2016;58:50-9.

78. Taylor L, Watkins S, Marshall H, et al. The impact of different environmental conditions on cognitive function: a focused review. Front Physiol. 2015;6:372.

79. Coull N, Chrismas B, Watson P, et al. Tyrosine ingestion and its effects on cognitive and physical performance in the heat. Med Sci Sports Exerc. 2015;48:277-86.

80. Gaoua N. Cognitive function in hot environments: a question of methodology. Scand J Med Sci Sports. 2010;20(Suppl 3):60-70.

81. Racinais S, Gaoua N, Grantham J. Hyperthermia impairs shortterm memory and peripheral motor drive transmission. J Physiol. 2008;586:4751-62.

82. de Aquino Lemos V, Antunes HKM, dos Santos RVT, et al. High altitude exposure impairs sleep patterns, mood, and cognitive functions. Psychophysiology. 2012;49:1298-306.

83. Yan X, Zhang J, Gong Q, et al. Prolonged high-altitude residence impacts verbal working memory: an fMRI study. Exp Brain Res. 2011;208:437-45.

84. Willmott AGB, Gibson OR, Hayes M, et al. The effects of single versus twice daily short term heat acclimation on heat strain and $3000 \mathrm{~m}$ running performance in hot, humid conditions. J Therm Biol. 2016;56:59-67.

85. Amorim FT, Fonseca IT, Machado-Moreira CA, et al. Insights into the role of heat shock proteins 72 to whole-body heat acclimation in humans. Temperature. 2015;2:499-505.

86. McClung JP, Hasday JD, He J-RR, et al. Exercise-heat acclimation in humans alters baseline levels and ex vivo heat 
inducibility of HSP72 and HSP90 in peripheral blood mononuclear cells. Am J Physiol Regul Integr Comp Physiol. 2008;294:R185-91.

87. Taylor L, Hillman A, Midgley A. Hypoxia mediated prior induction of monocyte-expressed HSP72 and HSP32 provides protection to the disturbances to redox balance associated with human sub-maximal aerobic exercise. Amino Acids. 2012;43:1933-44.

88. Taylor L, Midgley A, Chrismas B. The effect of acute hypoxia on heat shock protein 72 expression and oxidative stress in vivo. Eur J Appl Physiol. 2010;109:849-55.

89. Taylor L, Midgley AW, Chrismas B, et al. Daily hypoxia increases basal monocyte HSP72 expression in healthy human subjects. Amino Acids. 2011;40:393-401.

90. Ritossa FM. A new puffing pattern induced by temperature shock and DNP in Drosophila. Experientia. 1962;18:571-3.

91. Kampinga HH, Hageman J, Vos MJ, et al. Guidelines for the nomenclature of the human heat shock proteins. Cell Stress Chaperones. 2009;14:105-11.

92. Moran DS, Eli-Berchoer L, Heled Y, et al. Heat intolerance: does gene transcription contribute? J Appl Physiol. 2006;100:1370-6.

93. Kuennen M, Gillum T, Dokladny K, et al. Thermotolerance and heat acclimation may share a common mechanism in humans. Am J Physiol Regul Integr Comp Physiol. 2011;301:R524-33.

94. Maloyan A, Horowitz M. beta-Adrenergic signaling and thyroid hormones affect HSP72 expression during heat acclimation. J Appl Physiol. 2002;93:107-15.

95. Tuttle JA, Castle PC, Metcalfe AJ, et al. Downhill running and exercise in hot environments increase leukocyte Hsp 72 (HSPA1A) and Hsp90 $\alpha$ (HSPC1) gene transcripts. J Appl Physiol. 2015;118:996-1005.

96. Egan B, Zierath JR. Exercise metabolism and the molecular regulation of skeletal muscle adaptation. Cell Metab. 2013;17:162-84.

97. Coffey VG, Hawley JA. The molecular bases of training adaptation. Sports Med. 2007;37:737-63.

98. Sonna LA, Fujita J, Gaffin SL, et al. Invited review: effects of heat and cold stress on mammalian gene expression. J Appl Physiol. 2002;92:1725-42.

99. Horowitz M. Epigenetics and cytoprotection with heat acclimation. J Appl Physiol. 2016;120:702-10.

100. Horowitz M. Heat acclimation, epigenetics, and cytoprotection memory. Compr Physiol. 2014;4:199-230.

101. Jain K, Suryakumar G, Ganju L, et al. Differential hypoxic tolerance is mediated by activation of heat shock response and nitric oxide pathway. Cell Stress Chaperones. 2014;19:801-12.

102. Magalhães FDC, Amorim FT, Passos RLF, et al. Heat and exercise acclimation increases intracellular levels of Hsp72 and inhibits exercise-induced increase in intracellular and plasma Hsp72 in humans. Cell Stress Chaperones. 2010;15:885-95.

103. Gibson OR, Tuttle JA, Watt PW, et al. Hsp72 and Hsp90 $\alpha$ mRNA transcription is characterised by large, sustained changes in core temperature during heat acclimation. Cell Stress Chaperones. 2016;21:1021-35.

104. Morton JP, Maclaren DPM, Cable NT, et al. Elevated core and muscle temperature to levels comparable to exercise do not increase heat shock protein content of skeletal muscle of physically active men. Acta Physiol (Oxf). 2007;190:319-27.

105. Henstridge DC, Febbraio MA, Hargreaves M. Heat shock proteins and exercise adaptations. Our knowledge thus far and the road still ahead. J Appl Physiol. 2016;120:683-91.

106. Fehrenbach E, Niess AM, Veith R, et al. Changes of HSP72expression in leukocytes are associated with adaptation to exercise under conditions of high environmental temperature. J Leukoc Biol. 2001;69:747-54.
107. Khassaf M, Child RB, McArdle A, et al. Time course of responses of human skeletal muscle to oxidative stress induced by nondamaging exercise. J Appl Physiol. 2001;90:1031-5.

108. Febbraio MA, Steensberg A, Walsh R, et al. Reduced glycogen availability is associated with an elevation in HSP72 in contracting human skeletal muscle. J Physiol. 2002;538:911-7.

109. Peart D, McNaughton L, Midgley A. Pre-exercise alkalosis attenuates the heat shock protein 72 response to a single-bout of anaerobic exercise. J Sci Med Sport. 2011;14:435-40.

110. Stary CM, Hogan MC. Cytosolic calcium transients are a determinant of contraction-induced HSP72 transcription in single skeletal muscle fibers. J Appl Physiol. 2016;120:1260-6.

111. Morton JP, Kayani AC, McArdle A, et al. The exercise-induced stress response of skeletal muscle, with specific emphasis on humans. Sports Med. 2009;39:643-62.

112. Yamada P, Amorim F, Moseley P, et al. Heat shock protein 72 response to exercise in humans. Sports Med. 2008;38:715-33.

113. Leon LR. Common mechanisms for the adaptive responses to exercise and heat stress. J Appl Physiol. 2016;120:662-3.

114. Dokladny K, Zuhl MN, Moseley PL. Intestinal epithelial barrier function and tight junction proteins with heat and exercise. J Appl Physiol. 2016;120:692-701.

115. Zuhl MN, Lanphere KR, Kravitz L, et al. Effects of oral glutamine supplementation on exercise-induced gastrointestinal permeability and tight junction protein expression. J Appl Physiol. 2014;116:183-91.

116. Wischmeyer PE, Kahana M, Wolfson R, et al. Glutamine induces heat shock protein and protects against endotoxin shock in the rat. J Appl Physiol. 2001;90:2403-10.

117. Van Molle W, Wielockx B, Mahieu T, et al. HSP70 protects against TNF-induced lethal inflammatory shock. Immunity. 2002;16:685-95.

118. Leon LR, Bouchama A. Heat stroke. Compr Physiol. 2015;5(2):611-47.

119. Henstridge DC, Bruce CR, Drew BG, et al. Activating HSP72 in rodent skeletal muscle increases mitochondrial number and oxidative capacity and decreases insulin resistance. Diabetes. 2014;63:1881-94.

120. Shiota M, Kusakabe H, Izumi Y, et al. Heat shock cognate protein 70 is essential for Akt signaling in endothelial function. Arterioscler Thromb Vasc Biol. 2010;30:491-7.

121. Bruns AF, Yuldasheva N, Latham AM, et al. A heat-shock protein axis regulates VEGFR2 proteolysis, blood vessel development and repair. PLoS One. 2012;7:e48539.

122. Vogt M, Puntschart A, Geiser J, et al. Molecular adaptations in human skeletal muscle to endurance training under simulated hypoxic conditions. J Appl Physiol. 2001;91:173-82.

123. Levine B, Stray-Gundersen J. "Living high-training low": effect of moderate-altitude acclimatization with low-altitude training on performance. J Appl Physiol. 1997;83:102-12.

124. Kim T-K, Na HJ, Lee WR, et al. Heat shock protein 70-1A is a novel angiogenic regulator. Biochem Biophys Res Commun. 2016;469:222-8.

125. Ribeil J-A, Zermati Y, Vandekerckhove J, et al. Hsp70 regulates erythropoiesis by preventing caspase-3-mediated cleavage of GATA-1. Nature. 2007;445:102-5.

126. Ribeil J-AX, Zermati Y, Kersual J, et al. Hsp70 is a new major regulator of erythropoiesis by preventing caspase-3-mediated cleavage of GATA-1. Blood. 2004;104:581.

127. Brouet A, Sonveaux P, Dessy C, et al. Hsp90 ensures the transition from the early $\mathrm{Ca} 2+$-dependent to the late phosphorylation-dependent activation of the endothelial nitric-oxide synthase in vascular endothelial growth factor-exposed endothelial cells. J Biol Chem. 2001;276:32663-9.

128. Literáti-Nagy B, Kulcsár E, Literáti-Nagy Z, et al. Improvement of insulin sensitivity by a novel drug, BGP-15, in insulin- 
resistant patients: a proof of concept randomized double-blind clinical trial. Horm Metab Res. 2009;41:374-80.

129. Mee JA, Gibson OR, Tuttle JA, et al. Leukocyte Hsp72 mRNA transcription does not differ between males and females during heat acclimation. Temperature. 2016;3:549-56.

130. Morton JP, Holloway K, Woods P, et al. Exercise training-induced gender-specific heat shock protein adaptations in human skeletal muscle. Muscle Nerve. 2009;39:230-3.

131. Cotter JD, Tipton MJ. Moving in extreme environments: what's extreme and who decides? Extrem Physiol Med. 2014;3:11.

132. Christoforidi V, Koutlianos N, Deligiannis $P$, et al. Heart rate variability in free diving athletes. Clin Physiol Funct Imaging. 2012;32:162-6.

133. Huang K-L, Wu C-P, Chen Y-L, et al. Heat stress attenuates air bubble-induced acute lung injury: a novel mechanism of diving acclimatization. J Appl Physiol. 2003;94:1485-90.

134. Arieli Y, Eynan M, Gancz H, et al. Heat acclimation prolongs the time to central nervous system oxygen toxicity in the rat: possible involvement of HSP72. Brain Res. 2003;962:15-20.

135. Djurhuus R, Nossum V, Lundsett N, et al. Simulated diving after heat stress potentiates the induction of heat shock protein 70 and elevates glutathione in human endothelial cells. Cell Stress Chaperones. 2010;15:405-14.

136. Fismen L, Hjelde A, Svardal AM, et al. Differential effects on nitric oxide synthase, heat shock proteins and glutathione in human endothelial cells exposed to heat stress and simulated diving. Eur J Appl Physiol. 2012;112:2717-25.

137. Golden FS, Tipton MJ. Human adaptation to repeated cold immersions. J Physiol. 1988;396:349-63.

138. Stocks JM, Taylor NAS, Tipton MJ, et al. Human physiological responses to cold exposure. Aviat Space Environ Med. 2004;75:444-57.

139. Stocks JM, Patterson MJ, Hyde DE, et al. Metabolic habituation following repeated resting cold-water immersion is not apparent during low-intensity cold-water exercise. J Physiol Anthropol Appl Human Sci. 2001;20:263-7.

140. Mazzeo RS, Wolfel EE, Butterfield GE, et al. Sympathetic response during 21 days at high altitude $(4,300 \mathrm{~m})$ as determined by urinary and arterial catecholamines. Metabolism. 1994;43:1226-32.

141. Davis TRA. Chamber cold acclimatization in man. J Appl Physiol. 1961;16:1011-5.

142. van der Lans AAJJ, Hoeks J, Brans B, et al. Cold acclimation recruits human brown fat and increases nonshivering thermogenesis. J Clin Invest. 2013;123:3395-403.

143. Young AJ, Muza SR, Sawka MN, et al. Human thermoregulatory responses to cold air are altered by repeated cold water immersion. J Appl Physiol. 1986;60:1542-8.

144. Young AJ, Muza SR, Sawka MN, et al. Human vascular fluid responses to cold stress are not altered by cold acclimation. Undersea Biomed Res. 1987;14:215-28.

145. Lapp MC, Gee GK. Human acclimatization to cold water immersion. Arch Environ Health. 1967;15:568-79.

146. Radomski MW, Boutelier C. Hormone response of normal and intermittent cold-preadapted humans to continuous cold. J Appl Physiol. 1982;53:610-6.

147. Tipton MJ, Wakabayashi H, Barwood MJ, et al. Habituation of the metabolic and ventilatory responses to cold-water immersion in humans. J Therm Biol. 2013;38:24-31.

148. Brazaitis M, Eimantas N, Daniuseviciute L, et al. Time course of physiological and psychological responses in humans during a 20-day severe-cold-acclimation programme. PLoS One. 2014;9:e94698.
149. Muller MD, Kim C-H, Bellar DM, et al. Effect of cold acclimatization on exercise economy in the cold. Eur $\mathbf{J}$ Appl Physiol. 2012;112:795-800.

150. Shephard RJ. Metabolic adaptations to exercise in the cold. Sports Med. 1993;16:266-89.

151. Mäkinen TM, Palinkas LA, Reeves DL, et al. Effect of repeated exposures to cold on cognitive performance in humans. Physiol Behav. 2006;87:166-76.

152. Tipton MJ, Mekjavic IB, Eglin CM. Permanence of the habituation of the initial responses to cold-water immersion in humans. Eur J Appl Physiol. 2000;83:17-21.

153. Chauhan E, Bali A, Singh N, et al. Cross stress adaptation: phenomenon of interactions between homotypic and heterotypic stressors. Life Sci. 2015;137:98-104.

154. Teigen LE, Orczewska JI, McLaughlin J, et al. Cold acclimation increases levels of some heat shock protein and sirtuin isoforms in threespine stickleback. Comp Biochem Physiol A Mol Integr Physiol. 2015;188:139-47.

155. Wellmann S, Bührer C, Moderegger E, et al. Oxygen-regulated expression of the RNA-binding proteins RBM3 and CIRP by a HIF-1-independent mechanism. J Cell Sci. 2004;117:1785-94.

156. Auer RN. Non-pharmacologic (physiologic) neuroprotection in the treatment of brain ischemia. Ann NY Acad Sci. 2001;939:271-82.

157. Polderman KH. Induced hypothermia and fever control for prevention and treatment of neurological injuries. Lancet. 2008;371:1955-69.

158. Matz JM, LaVoi KP, Moen RJ, et al. Cold-induced heat shock protein expression in rat aorta and brown adipose tissue. Physiol Behav. 1996;60:1369-74.

159. Johnson JD, Campisi J, Sharkey CM, et al. Adrenergic receptors mediate stress-induced elevations in extracellular Hsp72. J Appl Physiol. 2005;99:1789-95.

160. Leeder J, Gissane C, van Someren K, et al. Cold water immersion and recovery from strenuous exercise: a meta-analysis. Br J Sports Med. 2012;46:233-40.

161. Tipton MJ. The initial responses to cold-water immersion in man. Clin Sci (Lond). 1989;77:581-8.

162. Ihsan M, Watson G, Choo HUIC, et al. Postexercise muscle cooling enhances gene expression of PGC-1 $\alpha$. Med Sci Sport Exerc. 2014;46:1900-7.

163. Pournot H, Bieuzen F, Duffield R, et al. Short term effects of various water immersions on recovery from exhaustive intermittent exercise. Eur J Appl Physiol. 2011;111:1287-95.

164. Ihsan M, Markworth JF, Watson G, et al. Regular postexercise cooling enhances mitochondrial biogenesis through AMPK and p38 MAPK in human skeletal muscle. Am J Physiol Regul Integr Comp Physiol. 2015;309(3):286-94.

165. Ihsan M, Watson G, Abbiss CR. What are the physiological mechanisms for post-exercise cold water immersion in the recovery from prolonged endurance and intermittent exercise? Sports Med. 2016;46:1095-109.

166. Al Haddad H, Parouty J, Buchheit M. Effect of daily cold water immersion on heart rate variability and subjective ratings of well-being in highly trained swimmers. Int J Sports Physiol Perform. 2012;7:33-8.

167. Hausswirth C, Duffield R, Pournot H, et al. Postexercise cooling interventions and the effects on exercise-induced heat stress in a temperate environment. Appl Physiol Nutr Metab Appl Nutr Metab. 2012;37:965-75.

168. Aguiar PF, Magalhães SM, Fonseca IAT, et al. Post-exercise cold water immersion does not alter high intensity interval training-induced exercise performance and $\mathrm{Hsp} 72$ responses, but enhances mitochondrial markers. Cell Stress Chaperones. 2016;21:793-804. 
169. Figueiredo C, Roberts LA, Markworth JF, et al. Impact of resistance exercise on ribosome biogenesis is acutely regulated by post-exercise recovery strategies. Physiol Rep. 2016;4:1-12.

170. Roberts LA, Raastad T, Markworth JF, et al. Post-exercise cold water immersion attenuates acute anabolic signalling and long- term adaptations in muscle to strength training. J Physiol. 2015;593:4285-301.

171. Murray A, Cardinale M. Cold applications for recovery in adolescent athletes: a systematic review and meta analysis. Extrem Physiol Med. 2015;4:17. 